\title{
Proton beam therapy for cancer in the era of precision medicine
}

\author{
Man $\mathrm{Hu}^{1,2,3}$, Liyang Jiang ${ }^{1,2,3}$, Xiangli Cui ${ }^{4}$, Jianguang Zhang ${ }^{5}$ and Jinming $\mathrm{Yu}^{1,2,3^{*}}$
}

\begin{abstract}
Precision radiotherapy, which accurately delivers the dose on a tumor and confers little or no irradiation to the surrounding normal tissue and organs, results in maximum tumor control and decreases the toxicity to the utmost extent. Proton beam therapy (PBT) provides superior dose distributions and has a dosimetric advantage over photon beam therapy. Initially, the clinical practice and study of proton beam therapy focused on ocular tumor, skull base, paraspinal tumors (chondrosarcoma and chordoma), and unresectable sarcomas, which responded poorly when treated with photon radiotherapy. Then, it is widely regarded as an ideal mode for reirradiation and pediatrics due to reducing unwanted side effects by lessening the dose to normal tissue. During the past decade, the application of PBT has been rapidly increasing worldwide and gradually expanding for the treatment of various malignancies. However, to date, the role of PBT in clinical settings is still controversial, and there are considerable challenges in its application. We systematically review the latest advances of PBT and the challenges for patient treatment in the era of precision medicine.
\end{abstract}

\section{Background}

Radiotherapy (RT) is an established treatment modality of malignant tumors. Currently, photon beam therapy is the most widely used in clinical settings. Intensity-modulated photon radiotherapy (IMRT) was introduced in the mid-1990s, and it took the radiotherapy with photons to a huge leap forward. As the development of IMRT, it has been considered to be the advanced and the standard of treatment for many malignancies [1]. Although the IMRT technique can typically provide a more conformal dose distribution than the traditional RT mode, it is necessary to improve the tumor control and overall survival (OS), and reduce the RT toxicity. It is well known that the advantage of a proton beam is the physical characteristics of its depth-dose curve, with a dose peak (Bragg peak) at a well-defined depth in tissue (Fig. 1). For relatively shallow tumors, unlike the photon depth-dose curve showing an exponentially decreasing energy deposition with increasing depth in tissue, the Bragg peak allows for rapid fall-off of the radiation dose at the end of the range and a sharp lateral dose fall-off with the maximum energy deposition for each proton

\footnotetext{
* Correspondence: sdyujinming@163.com

'Shandong Cancer Hospital Affiliated to Shandong University, Jinan, China

${ }^{2}$ Shandong Academy of Medical Sciences, Jinan, China

Full list of author information is available at the end of the article
}

beam in the target region and almost no energy around it. Therefore, proton beam therapy (PBT) effectively allows the delivery of high-radiation doses to tumor cells and very low or zero doses to the normal cells, which is recognized as an ideal therapy modality for treatment of malignant diseases, especially for organs at risk (OARs) with less toxicity. As Dr. Herman Suit in the department of radiation oncology of Massachusetts General Hospital (MGH) said: "No advantage to any patient for any irradiation of any normal tissue exists; and radiation complication never occurs in nonirradiated tissues."

In 1946, Robert R. Wilson proposed to use accelerator-produced beams of protons to treat patients with deep-seated tumors [2]. In 1954, the first patient with breast cancer was treated with proton radiation of the pituitary in the Berkeley Radiation Laboratory [3]. In 1961, protons commenced to be used for clinical treatment at Harvard Cyclotron Laboratory [4]. Initially, the clinical practice and research of PBT only focused on the tumors near a critical structure or those that responded poorly to photon radiotherapy such as ocular tumors, skull base tumors, paraspinal tumors, and unresectable sarcomas. Over the next 60 years, with the vast development of technology, the application of PBT has been gradually expanding to various neoplasms. Although increasingly more evidence has been indicated 


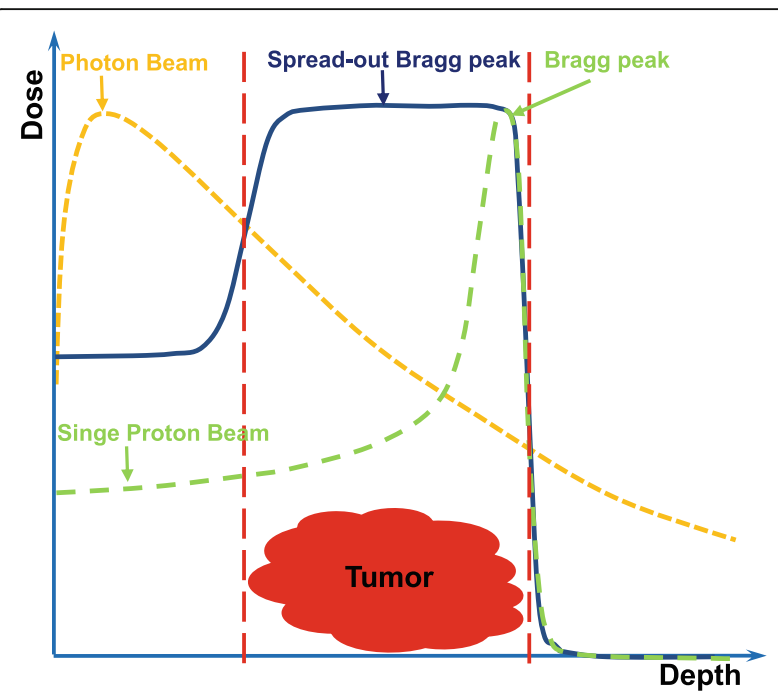

Fig. 1 The diagram of dose distributions for photon (dashed yellow line), single proton beam (dashed green line) as a function of penetration depth in tumor (normalized to the maximum dose), and spread-out proton beam (solid blue line)

for the advantages of PBT in clinical experience, PBT is not good for all cases all of the time. It is very important to understand the benefits and limitations of protons as well as the biology and the behavior of the tumor. In this review, we summarized the latest advances and clinical applications of PBT. We also considered the challenges of treatment optimization in the era of precision medicine.

\section{Latest clinical studies of PBT}

The dosimetry advantage of protons over photons has already been established (which is not reviewed in the article). However, do the potential advantages of the proton beam significantly transfer into clinical benefits for patients? Can the advanced techniques such as $360^{\circ}$ rotational gantries and intensity-modulated proton therapy (IMPT) further minimize toxicity and/or improve the clinical outcome? To date, there is not enough evidence to answer these questions due to small cohorts of patients in most published studies and the limited prospective data of comparisons between proton and photon radiotherapy. In this part, we present the clinical experiences and studies in the past few years, which may be provide a valuable understanding of the true value and advantage of PBT.

\section{Reirradiation}

Reirradiation may provide the best chance of long-term disease control and even a potential cure for the patients who truly undergo local and/or regional recurrence and who would not develop distant metastasis. The physical characteristics of PBT are particularly suited for reirradiation, which has been reported in head and neck cancer (HNC), thoracic cancers and liver cancer.

The largest report of recurrent HNC to date was an analysis of 92 patients treated with a proton beam using passive scatter technique reirradiation by Romesser et al. [5]. The median doses were $60.6 \mathrm{~Gy}$, and the 1 year cumulative incidence of locoregional failure (LRF), actuarial freedom of distant metastasis (FDM), and overall survival (OS) were $25.1 \%, 84.0 \%$, and $65.2 \%$, respectively. Eighty-seven (94.6\%) patients completed the reirradiation course. Acute grade $\geq 3$ toxicities of mucositis, dysphagia, esophagitis, and dermatitis accounted for $9.9 \%$, $9.1 \%, 9.1 \%$, and $3.3 \%$, respectively. Late grade $\geq 3$ adverse events included skin (8.7\%) and dysphagia (7.1\%), and only two patients $(2.2 \%)$ underwent grade 5 treatmentrelated bleeding toxicity. Phan et al. [6] evaluated 60 HNC patients receiving proton beam reirradiation. Twenty-five percent patients $(15 / 60)$ received passive scatter proton therapy (PSPT), and 75\% (45/60) received IMRT. The 1 year rates of locoregional failure-free survival (LRFFS), progression-free survival (PFS), OS, and distant metastasis-free survival (DMFS) were 68.4\%, $60.1 \%, 83.8 \%$, and $74.9 \%$, respectively. Acute grade 3 toxicity occurred in $30 \%$ patients (18), and $22 \%$ (13) needed a feeding tube. The 1-year rates of late grade 3 toxicity and feeding tube independence were $16.7 \%$ and $2.0 \%$, respectively. Three patients may have died due to reirradiation-related toxicity. For patients with recurrent $\mathrm{HNC}$, it is safe and effective to reirradiate disease by utilizing proton beam, which has acceptable rates of complications and durable tumor control and survival.

Because more patients with non-small cell lung cancer (NSCLC) have better survival, recurrence can occur more often in the previously irradiated area or adjacent area. Earlier published studies had explored the role of proton beam reirradiation for recurrent NSCLC patients, and most were focused on the palliative intent with lower overall doses. Recently, with definitive intent, Chao et al. [7] have reported the safety/feasibility of PBT for locally recurrent NSCLC $(n=57)$ in a multi-center prospective study. More than $90 \%$ of patients completed the reirradiation course. With a median dose of $66.6 \mathrm{~Gy}$, locoregional control (LRC) was 75\%, with 1- and 2-year OS rates of $59 \%$ and $43 \%$, PFS of $58 \%$ and $38 \%$, respectively. Twenty-four patients (42\%) developed grade $\geq 3$ acute and/or late toxicities. Six patients experienced grade 5 toxicities. In the study, the proton plan was largely double-scatter $(n=34$ [59.6\%]) or uniform scanning $(n=17$ [29.8\%]); only $10.6 \%$ were the IMPT technique, which spares the esophageal area and heart better with lower toxicity than PSPT. Ho et al. [8] have reported a retrospective analysis of 27 patients with reirradiation of thoracic malignancies using the IMPT technique delivery of a higher dose of radiation (median 
dose of 66 Gy). Twenty-two patients (81\%) were treated for NSCLC. The satisfactory outcomes revealed that patients who received the dose $\geq 66$ Gy had increased 1 -year freedom rates of local failure (LF) (100\% vs $49 \%$; $P=0.013$ ), LRF ( $84 \%$ vs $23 \% ; P=0.035$ ), and $\mathrm{PFS}(76 \%$ vs $14 \% ; P=0.050$ ), while no grade $\geq 4$ toxicities occurred and only 2 patients (7\%) experienced late grade 3 pulmonary toxicity. These studies demonstrate that PBT can provide benefits recurrent NSCLC patients, especially for metastatic lymph nodes in mediastinum, and allow more patients receiving a definitive concurrent chemoradiotherapy.

The feasibility and efficacy of repeated PBT for intrahepatic recurrence or metastasis has been evaluated. Oshiro et al. [9] reported that among the 83 patients with liver cancer who received definitive repeated PBT, the 5-year survival rate of the whole group is nearly $50 \%$, and no patient has radiation-induced liver disease. For reirradiation, it is critical to select the proper patient with the tumor volume and location.

\section{Pediatric cancers}

With more data from children treated with PBT, the proton beam model policy adopted by the American Society of Radiation Oncology in 2017 supports PBT in children with solid neoplasms, and it is now an option for many Children's Oncology Group (COG) protocols [10]. Many studies have confirmed the feasibility of PBT in pediatric cancer and achieved excellent outcomes compared to photon therapy. The advantage of PBT is recognized for craniospinal irradiation. A phase II clinical study reported the long-term results of PBT in 59 patients (aged 3-21 years) with medulloblastoma [11]. Patients received chemotherapy and had a median craniospinal irradiation dose of 23.4 Gy (RBE) followed by a boost dose of 54 Gy (RBE). The 5-year cumulative incidence of severe hearing loss was $16 \%$. There were no late toxicities of the heart, lungs, and digestive tract side effects, and no second primary tumor occurred, which was significantly better than that of photon therapy; the notable finding was that the intelligence quotient (IQ) of patients using PBT decreased slower than that using photon therapy. The rates of PFS and OS at 5 years were $80 \%$ and $83 \%$, respectively. Several studies reported that PBT has been used in the treatment of retinoblastoma, which is a common pediatric intraocular tumor. Mouw et al. [12] reported long-term outcomes for retinoblastoma with PBT. There were no patients died of retinoblastoma or developed metastasis at a median follow-up of 8 years. Eleven of 60 irradiated tumors were enucleated, mainly due to tumor progression. Twelve eyes developed ocular complications requiring intervention, which mainly included cataract, radiation retinopathy, glaucoma, and neovascularization. Various other pediatric cancers including chordoma and chondrosarcoma [13], ependymoma [14], craniopharyngioma [15], low-grade glioma [16], atypical teratoid rhabdoid tumor [17], and Ewing sarcoma [18] were treated with PBT, which is similar in adults, resulting in acceptable toxicities and showing similar survival outcomes to conventional radiotherapy.

With the prolongation of the survival of pediatric cancers, the late response from radiotherapy has received increasing attention. Growing evidence has demonstrated that PBT provide a health outcome benefit in pediatric patients, including radiation-associated late endocrine dysfunction, cognitive ability, and quality of life (QoL). Eaton et al. [19] compared the long-term clinical data in hormone levels after proton and photon irradiation. The results showed that PBT was associated with a reduced risk of hypothyroidism, sex hormone deficiency, and requirement for any endocrine replacement therapy compared to photon therapy, but no significant difference was found in the incidence of growth hormone deficiency, adrenal insufficiency, or precocious puberty. Pulsifer et al. [20] evaluated the cognitive function after PBT in 60 patients with pediatric CNS tumors including medulloblastoma, glioma, craniopharyngioma, ependymoma, and other brain tumors. During the follow-up of 2.5 years, there was a significant decline in the mean processing speed standard score, especially in younger patients (age at baseline $<12$ years). The cognitive outcomes compare favorably to published results for patients received photon RT. In a large prospective study, Yock et al. [21] first showed the improved long-term health-related quality of life (HRQoL) outcomes of children with brain tumors treated with PBT compared to photon RT. Leiser et al. [22] reported the QoL were encouraging in children with rhabdomyosarcoma who were treated with pencil-beam scattering (PBS). PBT appears to provide a low risk of second primary tumors, which is a very important problem for pediatric patients treated with RT. Children are in a period of growth and development, with high sensitiveness to radiation, and pediatric patients often have a long-survival time. As mentioned above, in the phase II clinical study [11], patients did not have an occurrence of a second primary tumor during the 7-year follow-up, while a meta-analysis showed the 10-year second tumor and second malignant tumor incidence rates after photon therapy [23] were $6.1 \%$ and $3.7 \%$, respectively. Sethi et al. [24] compared the risk of second malignancy in patients with retinoblastoma treated with photon therapy and PBT. At a median follow-up of 13.1 years in the photon therapy group and 6.9 years in the PBT group, the cumulative incidence of second malignancies (radiation-induced or in-field) at 10 years was significantly higher in photon therapy group than that in PBT group ( $14 \%$ vs. $0 \% ; P=0.015)$. An important challenge in children's PBT is the anesthesia due to the need of precision 
therapy. To ensure the precision of repeatability during treatment, most children need anesthesia, which may increase the associated risks.

\section{Neurological tumor}

PBT offers an alternative modality of RT available for neurological tumors in adults, potentially better sparing the surrounding normal brain tissue. Several prospective studies assessed the benefit of PBT in the management of glioma or meningiomas for the patients with lowgrade disease, who are usually young with typically long survival with the disease. A proton treatment protocol (NCT01024907) by Maquilan et al. [25] first reported the acute toxicities in patients with low-grade gliomas (LGGs) or meningioma who received 54 Gy. Among the 23 enrolled patients, only 1 patient suffered grade 3 fatigue during the treatment and the follow-up, and only 1 patient had a grade 3 headache at on-treatment visit week 3 . There was no observed grade $\geq 3$ acute toxicities in a multi-institution prospective study of 58 LGG patients who received PBT with $50.4 \mathrm{~Gy}$ to $54 \mathrm{~Gy}$ [26]. A study at MGH by Shih et al. [27] showed the findings of 20 LGG patients with the delivered dose of 54 Gy using PBT. The rates of PFS and OS at 5 years were $40 \%$ and $84 \%$, respectively. No grade 4 or 5 acute and late side effects occurred. All patients remained stable or slightly improved in neurocognitive status; 6 patients developed hormone deficiency, and there was no significant decrease in quality of life. The side effects of PBT are mild in clinical practice. McDonald et al. [28] reported the results of PBT in patients with World Health Organization (WHO) atypical meningiomas (grade 2). Twenty-two patients received a median dose of $63 \mathrm{~Gy}$ (RBE). With the median follow-up of 39 months, the 5-year estimate of LC was $71.1 \%$, and it was $87.5 \%$ following a RT dose $>60 \mathrm{~Gy}$ (RBE), compared to $50.0 \%$ for $\leq 60$ Gy (RBE). The data showed that PBT for meningiomas achieved favorable tumor control. For meningiomas that were partially adjacent to vital organs, PBT can be hypofractionated to better control the tumor, which has potential advantages. Vlachogiannis et al. [29] utilized IMPT $(4 \times 5$ Gy or $4 \times 6.6 \mathrm{~Gy}$ ) for treatment of intracranial meningioma (WHO I) in 170 patients, of which 155 were located in the skull base, and reported a 10 -year PFS rate of $85 \%$, with 6 patients with pituitary dysfunction, and 5 with signs of radiation necrosis (but only 1 requiring surgery, 5 with visual impairment, and 1 with a tumor cyst). Tumors located in the anterior cranial fossa were significantly increasing the risk of complications.

The preferred treatment of chordoma and chondrosarcoma is surgery. However, chordoma and chondrosarcoma, which originate in the skull base, are difficult to completely resect because the location is close to cranial nerves and blood vessels. To achieve a better local control, the radiation dose should be more than 74 Gy [30]. The treatment efficacy of photon therapy is unsatisfied due to the dose limitation of structures surrounding the tumor, such as the brain stem, temporal lobe and optic nerve, and the radiation dose of the tumor cannot be radical by photon therapy. However, PBT can increase the tumor dose and can better protect normal tissues. PBT has been used for the treatment of radio-resistant chordomas and chondrosarcomas for many decades. The patients with low-grade chondrosarcoma usually have a better longterm survival than those with chordoma in PBT and can even achieve a curable effect. Weber et al. [31] used PBS in 77 patients with skull-base chondrosarcoma. With a median dose of $70 \mathrm{~Gy}$, the actuarial LC and OS rates at 8 years were $89.7 \%$ and $93.5 \%$, respectively. Weber et al. have also reported long-term outcomes of skull-base low-grade chondrosarcoma and chordoma patients $(n=$ 151) treated with PBS. The rates of 7 -year LC were $70.9 \%$ and $93.6 \%$, respectively, and the rates of 7 -year OS were $72.9 \%$ and $94.1 \%$, respectively [32]. The toxicities of PBS for chordoma and chondrosarcoma are mild, which include optic nerve injury, brain necrosis, spinal cord necrosis, and hearing loss. A recent meta-analysis compared the effectiveness of PBT and photon therapy for chordoma [33]. The estimated 10-year OS rates of the PBT group reached $60 \%$, which was significantly higher than that of conventional photon therapy (21\%) and SRT (40\%). Feuvret et al. [34] reported the results of 159 chondrosarcoma patients treated with either PBT alone or combined with photon therapy. The median dose was $70.2 \mathrm{~Gy}$ (RBE) and with a median follow-up of 77 months, the LC and OS rates at 10 years were $93.5 \%$ and $87 \%$, respectively. Sixteen patients died, 13 of intercurrent disease and 3 of disease progression. There was no significant correlation between the incidence of toxicity and dose. Spinal cord necrosis is a serious side effect, and a study by Stieb et al. [35] has shown that dose constraints of $64 \mathrm{~Gy}$ as a dose to relative volume of $2 \%$ (D2\%) for the surface spinal cord and 54Gy for the center spinal cord seemed safe and appropriate for clinical use. Protons have been used in the treatment of functional pituitary adenomas [36], but the data are very limited to date.

\section{HNC}

PBT has been as an option when normal tissue constraints cannot be met by photon-based therapy for tumors of the ethmoid sinus, maxillary sinus, salivary gland, periorbital, nasopharynx, and mucosal melanoma, from the updated 2017 National Comprehensive Cancer Network (NCCN) guidelines. PBT is uniquely suited for $\mathrm{HNC}$ with the complex anatomy of tumors and important sensitive OARs, such as brain stem, optic chiasm, and optic nerve. The radiation targets of some $\mathrm{HNC}$, including major salivary gland cancer, skin cancer, early-stage tonsil cancer, and 
select oral cavity cancer, can be confined to unilateral head and neck, and therefore, lend themselves to the treatment of PSPT, which is better suited to superficial tumors which invade or abut critical structures. Romesser et al. [37] compared the treatment-related toxicities between patients receiving PSPT and IMRT in 41 patients with one side of major salivary gland tumors or cutaneous squamous cell cancers. The results showed that the rates of grade $\geq 2$ acute dysgeusia, mucositis, and nausea were significantly lower in PSPT group than those in IMRT group ( $5.6 \%$ vs. $65.2 \%, 16.7 \%$ vs. $52.2 \%, 11.1 \%$ vs. $56.5 \% ; P<0.001$, $<0.019,=0.003$, respectively). Russo et al. [38] have reported that 54 patients with stage III and IV SCC of the nasal cavity and paranasal sinus received PBT. The median dose was 72.8 Gy (RBE). At 5 years, the PBT yielded good actuarial LC rate of $80 \%$, and the OS rate of $47 \%$. Wound adverse events constituted the most common severe toxicity. Fifteen $\geq$ grade 3 side effects were observed. No grade 5 toxicity occurred. A meta-analysis study for nasal cavity and paranasal sinus tumors has showed a 5-year locoregional benefit and a slight OS advantage with PBT when compared to IMRT [39]. Decreased acute toxicities such as dysgeusia, mucositis, and nausea occurred in the PSPT group. However, the PSPT group had a higher incidence of grade $\geq 2$ dermatitis. Excellent LRC and survival rates were acquired on patients with nasopharyngeal carcinoma (NPC) using PBT. In a phase II trial, Chan et al. [40] assessed the efficacy and side effects of 23 patients with stage III-IVB NPC received concurrent chemo-PBT. With a median follow-up of 28 months, there were no local or regional recurrence occurred, and the 2-year disease-free survival (DFS) and OS were $90 \%$ and $100 \%$, respectively. There was no acute or late grade 4 or 5 treatment-related toxicities. A three-dimensional (3D) technique, PSPT with two posterior oblique fields, was used in the study. For treatment of regions in the nasopharynx or oropharynx with the bilateral neck, PSPT seemed to have difficulty achieving high-dose conformality, whereas IMPT has clear dosimetric advantages, providing the ability to cover a large field and deliver the conformity dose to complex head and neck tumors with irregular shapes. Lewis et al. [41] presented the clinical results for 10 patients treated with IMPT. No patients underwent any acute grade $\geq 4$ toxicities or any chronic grade $\geq 3$ toxicities. With the median follow-up of 24.5 months, 2 -year rates of LRC, DMFS, and OS were $100 \%$, $88.9 \%$, and $88.9 \%$, respectively. In a retrospective casecontrol study [42], IMPT-treated NPC patients $(n=$ 10) had significantly lower rates of gastrostomy tube insertion compared to IMRT-treated patients $(n=20)$ $(20 \%$ vs. $65 \%, P=0.02)$. There was no significant difference in chronic grade 3 toxicity, body weight lost, and swallowing dysfunction between type of radiation $(P=0.542,0.333$, and 0.175 , respectively). No patient developed LF in the IMPT group and 1 did in the IMRT group. One patient in each IMPT and IMRT group developed distant metastatic disease. Additionally, one patient in each group died. A series of studies on patients with (OPC) using IMPT were reported at MD Anderson Cancer Center. Sio et al. [43] retrospectively collected data from a prospective study and discovered that IMPT led to a lower symptom burden during the first 3 months after treatment for OPC patients who treated with IMPT and concurrent chemotherapy. In the same prospective study, Gunn et al. reported the clinical outcome of 50 patients with OPC received IMPT. The encouraging results showed the 2-year OS and PFS of $94.5 \%$ and $88.6 \%$, respectively, without grade $\geq 3$ acute and late toxicities found [44]. Then, the outcomes of the same cohort from 2011 to 2014 and 100 IMRT OPC patients from 2010 to 2012 were compared [45]. With a median follow-up of 32 months, the significant differences were not found in OS, PFS, acute grade $\geq 3$ dermatitis or mucositis between the two groups. The results of the abovementioned comparative studies of IMRT and IMPT in NPC and OPC may be biased due to the case-matched analysis. Additionally, the samples were small in the single-institution case, and the follow-up was relatively short for NPC or OPC patient with favorable OS.

\section{Eye tumors}

Although the incidence of eye tumors is very low, there is a relatively longstanding experience for plenty of patients with eye tumors treated with PBT, yielding excellent survival outcomes with ocular conservation and visual preservation. Lane et al. [46] showed the findings of PBT in 3088 patients with uveal melanoma. With the median follow-up of 12.3 years, the melanoma-related mortality rate was $24.6 \%$ in 15 years after treatment and $26.4 \%$ in 25 years. The highest annual rates of death from melanoma were reported 3 to 6 years after PBT, with the death rates of approximately $3-4 \%$. A study of 982 patients with uveal melanoma treated with PBT showed that the 10-year LC and overall eye retention rates were $96.4 \%$ and $95 \%$, respectively, with a median follow-up of 60.7 months [47]. The toxicities were acceptable, where 115 (12.1\%) patients developed glaucoma and 30 patients had to be enucleated. In a retrospective study that enrolled 336 patients with large choroidal melanomas, the rates of visual acuity retention at 10 years were $8.7 \%$ for $\geq 20 / 200$ and $22.4 \%$ for at least counting fingers; neovascular glaucoma was found in $25.3 \%$ patients. The rates of eye retained and tumor controlled were $70.4 \%$ and $87.5 \%$, respectively, at 10 years post-PBI therapy. The 10-year rates of all-cause mortality and dying of metastatic uveal melanoma were $60.7 \%$ 
and 48.5\%, respectively [48]. Verma et al. [49] reviewed the results of 14 studies of PBT for uveal melanoma, which was consistent with prior studies. In a retrospective study with 492 choroidal melanomas patients receiving PBT [50], the 5-year LC was high at 94\%, and the survival was not deteriorative. The mean baseline visual acuity, visual acuity $\geq 20 / 200$, neovascular glaucoma, and enucleation were in $31.7 \%$ (20/63), 20\%, 27\%, and $19.5 \%$, respectively. The study indicated that $\mathrm{PBT}$ was a safe strategy for large choroidal melanomas. Similarly, in order to achieve good vision function and cosmesis, PBT is an attractive RT mode for patients with periorbital tumors. At MD Anderson Cancer Center, 20 patients with lacrimal gland $(n=7)$, lacrimal sac/nasolacrimal duct $(n$ $=10)$, and eyelid $(n=3)$ underwent orbit-sparing surgery followed by PBT [51]. With a median follow-up of 27.1 months, no patient had local recurrence, only 1 suffered regional recurrence and another 1 distant metastasis. There were no patients who experienced acute grade 3 ocular disorders, acute and chronic grade $\geq 4$ toxicity. Meanwhile, the good local control has been obtained [52]. Among 11 patients who experienced orbit-sparing surgical resection followed by PBT and/or chemotherapy, 10 patients had post-treatment visual acuities better than 20/40 and were also satisfied with their cosmesis after eye-sparing surgery. PBT achieved good LC and was well tolerated with a good vision function and cosmesis.

The eye toxicities were acceptable for patients treated with PBT. Thariat et al. [53] showed the 5-year incidence of dry-eye syndrome and severe (grade 2-3) dry-eye syndrome was $23.0 \%$ and $10.9 \%$, respectively. Patients whose tumors located on the superotemporal or temporal lobe had a higher risk for severe dry-eye syndrome.

The lens is one of the most radiosensitive organs and can cause cataracts when exposed. PBT can better spare all or part of the lens than other forms of RT. The 5 -year incidence of cataract was $18.7 \%$, and the corresponding vision-impairing cataract rate was $12.8 \%$ of 1696 ocular melanomas by PBT [54]. For tumors which are located on the upper side of the choroid plexus, if the upper eyelid margin is not retracted out of the radiation field, patients abrade the cornea every time they are blinking. This may cause keratopathy, and it can become so severe as to cause corneal enucleation. However, transpalpebral (i.e., through closed eyelids) PBT of choroidal melanoma can spare the eyelid and avoid ocular surface complications without increasing failure of local control [55].

\section{NSCLC}

The toxicity of cardiopulmonary, lung, and spinal cord restricts the ascent of dose for patients with NSCLC by
RT with or without chemotherapy. PBT's early use in NSCLC was confined to small (stage I) tumors with conventional fraction, producing a high rate of LC. For stage I NSCLC, it is interesting in stereotactic body proton radiotherapy (SBPT). Loma Linda University reported clinical experiences in the early-stage NSCLC $(n=111)$ with SBPT [56]. With the dose escalated from $51 \mathrm{~Gy}$ to $70 \mathrm{~Gy}$ in 10 fractions, the OS was improved, with a 4 -year OS rate of $18 \%$ up to $51 \%(P=0.006)$. Chang et al. [57] have reported a modified less hypofractionated regimen of PBT with a total dose of 87.5 Gy and 2.5 Gy per fraction in 35 early-stage NSCLC patients. 5-year rates of local recurrence-free, regional recurrence-free, and DMFS were $85.0 \%, 89.2 \%$, and $54.4 \%$, respectively. On the basis of the encouraging results, MD Anderson Cancer initiated a phase II randomized trial of SBRT ( $n$ $=9)$ vs. SBPT $(n=10)$ in stage I-II or recurrent NSCLC [58]. Unfortunately, similar 3-year LC rates were reported, at $87.5 \%$ and $90 \%$ in these two groups, respectively. Larger cohort studies are needed regarding the safety and efficacy of SBPT in comparison to SBRT. Based on the dosimetric advantage, PBT has the potential to escalate the higher dose within target.

For patients with locally advanced NSCLC who received a high proton dose with or without chemotherapy have been reported. A retrospective study reported 35 patients with stage II-III NSCLC receiving PSPT [59]. With a mean dose of 78.3 Gy (RBE), 2-year local PFS was $65.9 \%$ and OS rate was $58.9 \%$. Severe toxicity was not observed. In a non-randomized prospective study [60], 134 NSCLC patients with stage II $(n=21)$ and stage III $(n=113)$ underwent PSPT concurrent with weekly chemotherapy. The rates of grade 3 and grade 4 toxicities were $12 \%$ and $0.7 \%$, respectively. This study demonstrated that a high proton dose of 60-74.1 Gy (RBE) was safe and tolerable with low toxicity. The median OS were 40.4 and 30.4 months for patients with stage II and stage III, respectively, and the promising 5-year OS rates was $25.3 \%$ for stage IIIA and $31.8 \%$ for stage IIIB. The results suggested that patients with larger tumors and centrally located lesions or those near the brachial plexus may be of benefit more with the use of PBS. Recently, Chang et al. [61] provided a phase II study which described the final outcome of concurrent chemotherapy and PSPT with 74 Gy for unresectable stage III NSCLC $(n=64)$. With a median follow-up of 27.3 months, the results showed favorable outcomes OS of $29 \%$, and PFS of $22 \%$ at 5 years. There was no acute or late grade 5 toxicity. The rate of three acute esophagitis was $5(8 \%)$. Late toxicities were not common: 1 patient experienced grade 3,1 grade 4 esophagitis, 8 grade 3 pneumonitis, 1 grade 4 bronchial fistula, and 2 grade 3 pericardial effusions. This is consistent with prior phase II studies, which indicated that concurrent a high proton dose and 
chemotherapy was well tolerated and effective for stage III NSCLC [62, 63]. Patients with locally advanced NSCLC received a high proton RT dose had excellent outcomes with tolerable toxicity. To confirm whether PBT could benefit local disease control and survival, Liao et al. conducted the first one randomized trial comparing PSPT $(n=57)$ with IMPT $(n=92)$ for patients with locally advanced NSCLC received concurrent chemotherapy [64]. Unfortunately, the significant difference was not observed in the grade $\geq 3$ radiation pneumonitis (IMRT vs. PSPT: $6.5 \%$ vs. $10.5 \%$; $P=0.537$ ) or local failure (IMRT vs. PSPT: $10.9 \%$ vs. $10.5 \% ; P=1.0$ ) after IMRT or PSPT. It should be noted that these above studies used PSPT, which may restrict the advantage of protons. Phase III trials (RTOG 1308) using IMPT with 70 Gy (RBE) vs. IMRT are ongoing [65]. The results may reveal whether PBT benefit the patients with advanced NSCLC or not.

\section{Breast cancer}

The clinical experiences with PBT for patients with breast cancer are limited, and fewer studies have centered on accessing the clinical outcomes of long-term follow-up. At first, studies using PBT for breast cancer focused on accelerated partial breast irradiation (APBI), where recurrence risk was low and treatment-related toxicity was less tolerable. One of the largest APBI study by Bush et al. [66] was reported with 40 Gy (RBE) in 10 daily fractions in 100 patients. With a median follow-up of 60 months, cosmesis was good to excellent in $90 \%$ patients, grade $\geq 3$ acute skin reaction was not occurred, yielding DFS and OS of $94 \%$ and $95 \%$, respectively. PBT is also a promising mode for adjuvant radiotherapy in breast cancer with nodal areas. Verma et al. [67] reported acute toxicities in 91 patients who had adjuvant breast/chest wall and regional nodal radiotherapy using PBS or PSPT with a median dose of $50.4 \mathrm{~Gy}$ (RBE). The median follow-up was 15.5 months. Grades 1, 2, and 3 dermatitis occurred in $23 \%, 72 \%$, and $5 \%$ of patients, respectively, and grades 1,2 , and 3 esophagitis arose in $31 \%$, 33\%, and $0 \%$, respectively. There are some studies that have reported the acute toxicities of PBT for patients treated with postoperative RT [68, 69]. Although the potential for PBT to prevent cardiac deaths is dosimetrically apparent [70], it needed to further evaluate whether PBT could actually reduce late cardiac toxicity due to the short of long-term follow-up data.

\section{Esophageal cancer (EC)}

Currently, IMRT is the most common radiation technique in treating EC. To date, the clinical experience of PBT for patients with EC has lack of institutional studies. Ishikawa et al. [71] performed definitive PBT and concurrent chemotherapy in 40 patients with esophageal squamous cell carcinoma. Patients received a total dose of $60 \mathrm{~Gy}$ (RBE), and an additional boost of 4-10 Gy (RBE) was given when residual tumors were suspected. There was no grade $\geq 3$ cardiopulmonary toxicities. The 3 -year rate of OS was 70\%, and 2-year rates of DFS and LRC were $77 \%$ and $66 \%$, respectively. Compared with squamous cell carcinoma, patients of adenocarcinoma had inferior outcomes; the 3-year rates of OS, relapse-free survival (RFS), DMFS, and LRF survival were $51.7 \%, 40.5 \%, 66.7 \%$, and $56.5 \%$, respectively. Recently, Prayongrat et al. [72] have reported excellent clinical outcomes of 19 patients with EC treated with concurrent chemo-radiotherapy using PBS. The median doses were $50.4 \mathrm{~Gy}$ (RBE) in 28 fractions. With a median follow-up time of 17 months, the OS was 39.2 months. The 1-year rates of OS, locoregional RFS, and DMFS were $100 \%, 88.8 \%$, and $72.9 \%$, respectively. Treatment was well tolerated with limited grade 3 toxicities. Clinically complete response was achieved in $84 \%$ of patients. Grade 3 esophagitis and fatigue occurred in three patients, and grade 3 esophageal strictures occurred in only 1 patient. The clinical outcomes of PBT combined with chemotherapy for EC were encouraging in the above studies. The comparison of clinical outcomes between proton and photon RT has only been reported in one retrospective study [73]. From 2007 to 2014, 343 EC patients treated with definitive chemo-radiotherapy were enrolled. Compared with IMRT $(n=211)$, PBT $(n=132)$ had significantly better OS, PFS, and DMFS $(P=0.011$, $0.001,0.031$, respectively), as well as marginally better LRFFS $(P=0.075)$. However, there was no significant difference in treatment-related toxicities rates between two groups. In the PBT group, most patients (94.7\%) received PSPT, and only $5.3 \%$ patients (7) were treated with IMPT. Subgroup analysis by clinical stage found significantly higher rates of OS $(34.6 \%$ vs $25.0 \%, P=0.038)$ and PFS $(33.5 \%$ vs $13.2 \%, P=0.005)$ at 5 years in the PBT group for stage III patients, but no significant differences in intergroup survival were observed for patients with stage I/II. The findings suggested that the theoretical advantage of PBT over photon therapy might turn into a survival benefit, especially in locally advanced disease.

Recently, one notable study at MD Anderson was reported that grade 4 lymphopenia during chemo-radiotherapy for EC was associated with poor overall and disease-specific survival outcomes, and OS in this group was significantly worse than the grade $0-2$ group, with a median OS 2.8 vs. 5.0 years $(P=0.027)$ [74]. The radiation type (photon-based VS. proton-based) significantly influenced the mean body dose exposure, which was a strong predictor for G4 nadir $(P<0.01)$. The important finding in the study was that PBT could reduce the low dose area, and then resulted in less lymphopenia risk. The study revealed that PBT could help to improve 
immune surveillance, and better tumor control may finally be a benefit from it. The critical role of protons for immune surveillance requires confirmation in further research.

\section{Liver cancer}

The tolerated dose of normal liver is relatively low, and $80 \%$ of patients with liver cancer have chronic liver disease, which further reduces the tolerated dose of normal liver. Although liver cancer cells are highly sensitive to radiation, the usage of photon $\mathrm{RT}$ is limited for liver cancer. However, PBT can significantly decrease the normal liver dose, and most of the normal liver can be completely unirradiated, which makes it possible to use dose escalation. A phase I study suggested that $72 \mathrm{GyE}$ in 24 fractions using PBT for patients with inoperable hepatocellular carcinoma (HCC) was safe and effective with a complete response (CR) rate of 100\%, 3-year local PFS rate of $83.3 \%$, DFS rate of $20.8 \%$, and OS rate of $73.3 \%$ [75]. Hong et al. [76] showed a multi-center phase II clinical study of high-dose, hypofractionated PBT for localized inoperable liver cancer. There were 83 patients enrolled. With a medium dose of $58 \mathrm{~Gy} / 15 \mathrm{~F}$, the median diameters of HCC and intrahepatic cholangio carcinoma were $5.0 \mathrm{~cm}$ and $6.0 \mathrm{~cm}$, respectively, of which $27.3 \%$ and $12.8 \%$ were multi-centric, and $29.5 \%$ and $28.2 \%$ had tumor vascular thrombosis. The rates of LC at 2 years were $94.8 \%$ and $94.1 \%$, and the rates of OS at 2 years were $63.2 \%$ and $46.5 \%$. The most common toxicities were fatigue, rash, nausea, or anorexia. Four patients had grade $\geq 3$ side effects: liver failure and ascites, thrombocytopenia, gastric ulcer, and elevated bilirubin. Recently, similar LC and OS of HCC over $5 \mathrm{~cm}$ after PBT (median dose of 72.6 Gy in 22 fractions) in 24 patients were reported by offering an effective and safe RT that yielded a 2-year LC and OS rate of $87 \%$ and $52.4 \%$ for 24 patients with HCC over $5 \mathrm{~cm}$ [77]. Bush et al. [78] compared the effects of PBT and transcatheter arterial chemoembolization for liver cancer. There was a trend toward improved 2 -year LC ( $88 \%$ vs. $45 \%, P=0.06)$ and PFS ( $48 \%$ vs. $31 \%, P=0.06)$ favoring the PBT group and significantly fewer hospitalization days were found in the PBT group. The data of long-term efficacy of PBT for patients with untreated HCC is limited. Fukuda et al. [79] reported the 5-year outcomes for 129 patients. Total PBT dose was 66.0 77.0 GyE in 10 35 fractions, the rates of LC, PFS, and OS at 5 years were $94 \%, 28 \%$, and $69 \%$ for $0 /$ A stage patients $(n=9 / 21), 87 \%, 23 \%$, and $66 \%$ for patients with B stage $(n=34)$, and $75 \%, 9 \%$, and $25 \%$ for those with $C$ stage $(n=65)$, respectively. For 15 patients with tumor thrombi in major vessels, the rates of LC and OS at 5 years were $90 \%$ and 34\%, respectively. There was no grade $\geq 3$ toxicity. PBT offered an effective and safe therapy for HCC patients with portal vein tumor thrombosis, which has limited treatment options. With a median dose of 55 Gy PBT at 20 22 fractions, a promising result was median OS of 13.2 months, the partial response of $55.6 \%$ (15/27), stable disease of $37 \%$ (10/27), and progressive disease of $7.4 \%(2 / 27)$. There was no toxicity of grade $\geq 3$. PBT is a promising RT modality to treat cancer thrombosis, which is the common complication for liver cancer with poor prognosis. With the high-dose PBT, more than $50 \%$ of tumor thrombosis can be alleviated and then significantly prolong the survival time of patients [80]. With the development of technology, the application of IMPT may further reduce the dose of normal liver, especially when the tumor is larger and deeper. However, when the tumor is close to the chest wall, the chest wall toxicity risk cannot be avoided without sacrificing the tumor coverage, and it may be reduced with continuously IMPT optimization [81].

\section{Prostate cancer}

PBT is the most widely used in the treatment of prostate cancer. Takagi et al. [82] reported the clinical outcomes in patients with limited stage prostate cancer received PSPT, which had the largest cohort of patients $(n=$ 1375 ) and the longest follow-up period to date. The conventional fractionation was used, and $99 \%$ of patients treated with $74 \mathrm{~Gy}$ (RBE). With a median follow-up of 70 months, for the low-, intermediate-, high-, and very high-risk groups, 8-year freedom from biochemical relapses were $95 \%, 87 \%, 71 \%$, and $55 \%$, respectively, and 8 -year cancer-specific survival rates were $100 \%, 99 \%$, $98 \%$, and $92 \%$, respectively. The findings revealed that the incidence of late genitourinary toxicity continued to increase beyond 5 years, whereas the incidence of late gastrointestinal toxicity had plateaued by 5 years. Similar results were reviewed in 1327 patients by Bryant et al. [83]. Ho et al. [84] evaluated long-term outcomes with a focus on sexual health for young patients treated with PSPT in a dose of 76-82 Gy (2 Gy/F) or 70-72.5 Gy (2.5 $\mathrm{Gy} / \mathrm{F})$. The results were shown that erections firm enough for sexual intercourse decreased from $90 \%$ (baseline) to $72 \%$ (1 year follow-up). Only $2 \%$ of patients underwent urinary incontinence with pads. The bowel habits mean score decreased from 96 at the baseline level to 88 at 1-year follow-up, but it increased to 93 at 5-year follow-up. The clinical outcomes of patients treated with PBT are superior to those treated with three-dimensional conformal radiation therapy photon, which were in other studies. To date, there are no prospective trials comparing the effectiveness and toxicities between proton and photon RT for patients with prostate cancer.

Hypofractionated PBT has been studied in prostate cancer and is expected to become an effective treatment approach. Henderson et al. [85] showed the results that the accelerated hypofractionated regimen for low-risk 
and intermediate-risk prostate cancer with $2.5 \mathrm{~Gy}$ per fraction; the 5-year OS rates were $96 \%$ and $96.4 \%$, respectively, while the 5 -year freedom from biochemical relapses were $98.3 \%$ and $92.7 \%$, respectively. The actuarial 5 -year rate of late radiation-related $\geq$ grade 3 gastrointestinal side effect was $0.5 \%$, and urologic toxicity was $1.7 \%$, which showed the hypofractionated regimen had high efficacy and was well-tolerated. Nakajima et al. [86] compared the differences in acute toxicity among patients with intermediate- and high-risk prostate cancer received conventional fractionated PBT $(2 \mathrm{~Gy} / \mathrm{F})$ and the hypofractionated regimen $(3 \mathrm{~Gy} / \mathrm{F})$. No severe acute side effect occurred in either group. Grade 2 acute genitourinary toxicities rates were $15 \%(n=38)$ in the conventional fractionated group and $5.9 \%(n=16)$ in the hypofractionated group $(P \leq 0.001)$, but no significant differences in acute gastrointestinal toxicity were found between both groups. The interim results of the PCG GU 002 trial showed that the hypofractionated regimen of $38 \mathrm{~Gy} \mathrm{RBE} \mathrm{(7.5} \mathrm{Gy} \mathrm{RBE/fraction)} \mathrm{for} \mathrm{low-risk} \mathrm{prostate}$ cancer patients was tolerated well, with no grade $\geq 3$ acute toxicity, and it revealed no apparent clinical difference in outcomes compared with conventional fractionation [87]. To reduce the rectal dose and toxicity, Chung et al. [88] inserted a spacer in the prerectal space and the thickness of the spacer was no less than $9 \mathrm{~mm}$ to yield the largest benefit. For prostate cancer treated with PBT, it is important to emphasize that patients with hip or femoral head replacement were not suitable for using two horizontal beams through the opposing right and left lateral femoral head, which is usually designed in IMPT planning. An alternative dose delivery technique is with two anterior-oblique beams, whereas it could increase the dose exposure to the rectum [89].

\section{The current challenges of proton therapy and its development in the future}

Growing application of PBT to treat patients with malignancy has been confirmed to be safe, precise, and efficient with a tolerant toxicity, resulting in expanding the clinical applications in spite of that the vast costs and building sites are required to install and maintain the PBT treatment machine. During the last decade, the proton facilities are most widely distributed worldwide. As of August 2018, there were approximately 70 proton centers in operation in the world, and 45 were under construction; more than 140,000 patients have been treated by PBT $[90,91]$. The statistics of proton centers and patient treated by PBT are shown in Table 1. As of November 13, 2017, there were approximately 300 clinical trials with PBT that are ongoing, and the detail is shown in Table 2 [92]. However, there are at least three limitations of published studies that evaluate the value of PBT. First, most studies were retrospective analyses.
Table 1 Facilities in operation patient statistics (last update August 2018) and facilities under construction (update July 2018)

\begin{tabular}{|c|c|c|c|c|}
\hline Status & Area & $\begin{array}{l}\text { Country/ } \\
\text { region }\end{array}$ & $\begin{array}{l}\text { Numbers } \\
\text { of proton } \\
\text { centers }\end{array}$ & $\begin{array}{l}\text { Total } \\
\text { patients } \\
\text { treated }\end{array}$ \\
\hline \multirow[t]{19}{*}{ Operation } & \multirow[t]{4}{*}{ Asia } & China & 2 & 1729 \\
\hline & & Japan & 13 & 23,035 \\
\hline & & South Korea & 2 & 2056 \\
\hline & & Taiwan, China & 1 & 1010 \\
\hline & \multirow[t]{10}{*}{ Europe } & Czech Republic & 1 & 2428 \\
\hline & & England & 2 & 3224 \\
\hline & & France & 3 & 14,881 \\
\hline & & Germany & 6 & 9752 \\
\hline & & Italy & 3 & 1302 \\
\hline & & Poland & 1 & 267 \\
\hline & & Russia & 3 & 5552 \\
\hline & & Sweden & 1 & 407 \\
\hline & & Switzerland & 1 & 8448 \\
\hline & & The Netherlands & 1 & 1 \\
\hline & \multirow{2}{*}{$\begin{array}{l}\text { North } \\
\text { America }\end{array}$} & USA & 27 & 72,009 \\
\hline & & Canada & 1 & 204 \\
\hline & Oceania & Australia & 1 & 79 \\
\hline & \multirow[t]{2}{*}{ Africa } & South Africa & 1 & 524 \\
\hline & & Total & 70 & 149,086 \\
\hline \multirow{18}{*}{$\begin{array}{l}\text { Under } \\
\text { construction }\end{array}$} & \multirow[t]{9}{*}{ Asia } & China & 7 & \\
\hline & & Japan & 5 & \\
\hline & & Thailand & 1 & \\
\hline & & South Korea & 1 & \\
\hline & & India & 2 & \\
\hline & & Emirate of Abu Dhabi & 1 & \\
\hline & & Singapore & 1 & \\
\hline & & Taiwan China & 2 & \\
\hline & & Saudi Arabia & 1 & \\
\hline & \multirow[t]{7}{*}{ Europe } & France & 1 & \\
\hline & & The Netherlands & 2 & \\
\hline & & Russia & 2 & \\
\hline & & UK & 6 & \\
\hline & & Denmark & 1 & \\
\hline & & Belgium & 1 & \\
\hline & & Slovak Republic & 1 & \\
\hline & \multirow[t]{2}{*}{$\begin{array}{l}\text { North } \\
\text { America }\end{array}$} & USA & 10 & \\
\hline & & Total & 45 & \\
\hline
\end{tabular}

Second, the prospective studies had small samples. Last, the data for comparisons between PBT and conventional RT were limited. Further prospective trials with modern 
Table 2 Clinical trials for proton beam therapy (update November 13, 2017)

\begin{tabular}{|c|c|c|}
\hline Indication: & Loc: & Links to protocols (clinicaltrials.gov and UMIN-CTR): \\
\hline \multirow[t]{8}{*}{ Pediatrics } & Craniopharyngioma & NCT01419067; NCT02792582 \\
\hline & $\begin{array}{l}\text { Central nervous system } \\
\text { tumors }\end{array}$ & NCT02559752; NCT01180881; NCT02112617 \\
\hline & Brain tumors & NCT00602667; NCT01288235; NCT01115777; NCT00105560; NCT03267836; NCT00238264; NCT03281889 \\
\hline & Head/neck & NCT02608762 \\
\hline & Bone & NCT00592293 \\
\hline & Rhabdomyosarcoma & NCT00592592 \\
\hline & $\begin{array}{l}\text { Lymphoma involving } \\
\text { mediastinum }\end{array}$ & NCT01751412 \\
\hline & Unclassified & NCT01502150; NCT02644993; NCT03223766; NCT01696721; UMIN000023170 \\
\hline \multirow[t]{4}{*}{ Head and neck } & Nasopharynx & NCT00592501; NCT01586767; NCT03274414 \\
\hline & Oropharynx & NCT01893307; NCT02663583; NCT02736786 \\
\hline & Esophageal & NCT01512589 \\
\hline & Unclassified & NCT01228448; NCT01627093; NCT01973179; NCT02838602; NCT02923570; NCT03183271 \\
\hline Lung & $\begin{array}{l}\text { Non-small cell lung } \\
\text { cancer }\end{array}$ & $\begin{array}{l}\text { NCT00614484; NCT01511081; NCT00495040; NCT01512589; NCT01165658; NCT00915005; CT01808677; } \\
\text { NCT00875901; NCT00881712; NCT01770418; NCT02029222; NCT02038413; NCT02844140; NCT01629498; } \\
\text { NCT01993810; NCT01076231; NCT01108666; NCT01126476; NCT02130427; NCT03087760; NCT01525446; } \\
\text { NCT01565772; NCT02314364; NCT02204761; NCT02172846; NCT02172846; NCT02073968; NCT01859650; } \\
\text { NCT02731001; UMINO00005585; NCT03132532; NCT03226925 }\end{array}$ \\
\hline \multirow[t]{4}{*}{ CNS } & Brain tumors & $\begin{array}{l}\text { NCT01854554; NCT01730950; NCT02179086; NCT01024907; NCT01180881; NCT0135805; NCT01228448; } \\
\text { NCT0328633; NCT02693990; NCT03286335; NCT01 165671; NCT02607397; NCT01730950; NCT02824731; } \\
\text { NCT02824731; NCT03180502; NCT03281889; NCT01117844; NCT01180881; NCT00798057 }\end{array}$ \\
\hline & Skull base & NCT01795300; NCT01182753; NCT01 182779 \\
\hline & Chondrosarcoma & NCT00496522 \\
\hline & Central nervous system & NCT01049230; NCT02559752; NCT02797366; NCT03055364 \\
\hline \multirow[t]{2}{*}{ Breast } & Partial breast & $\begin{array}{l}\text { NCT01839838; NCT01386697; NCT00599989; NCT02603341; NCT02199366; NCT02725840; NCT01340495; } \\
\text { NCT03270072; NCT03340402; NCT00614172; NCT01310530; NCT01766297; NCT01758445; NCT01245712; } \\
\text { NCT02453737; NCT03339934; UMIN000017579; UMIN000016206 }\end{array}$ \\
\hline & Lymph nodes & NCT02783690; NCT01365845 \\
\hline \multirow[t]{5}{*}{ Gl } & Liver & $\begin{array}{l}\text { NCT00614913; NCT01141478; NCT00857805; NCT01697371; NCT00976898; NCT00465023; NCT01239381; } \\
\text { NCT00662246; NCT01963429; NCT01643824; NCT02395523; NCT00426829; NCT01668134; NCT02632864; } \\
\text { NCT02571946; NCT02640924; UMINO00020596; NCT02802124; UMIN000020862; UMIN000002863; } \\
\text { UMIN000025342; UMIN000020596; UMIN000016574; NCT03186898 }\end{array}$ \\
\hline & Pancreas & $\begin{array}{l}\text { NCT01821729; NCT01591733; NCT00438256; NCT01494155; NCT00658801; NCT00658840; NCT00685763; } \\
\text { NCT00763516; NCT01553019; NCT02598349; NCT01683422; UMIN000020862; UMIN000008785; UMIN000012201 }\end{array}$ \\
\hline & Upper Gl & NCT01449864 \\
\hline & Rectum & NCT00503932; NCT03018418; NCT03098108 \\
\hline & Esophageal & NCT01512589; NCT01684904; NCT02023541; UMIN000015550; NCT03234842 \\
\hline \multirow[t]{2}{*}{ GU } & Prostate & $\begin{array}{l}\text { NCT02110849; NCT01709253; NCT03285815; NCT01811810; NCT01352429; NCT01045226; NCT01617161; } \\
\text { NCT02040610; NCT00969111; NCT00693238; NCT01368055; NCT01072513); NCT01040624; NCT01987193; } \\
\text { NCT02598349; NCT00489814; NCT01950351; NCT00388804; NCT01492972; NCT01603420; NCT01230866; } \\
\text { UMINO00020199; UMIN000010510; UMINO00017679; UMIN000017679; UMIN000020596; UMIN000003937; } \\
\text { NCT02766686; NCT02874014 }\end{array}$ \\
\hline & Bladder & NCT01520038 \\
\hline Lymphoma & Hodgkin lymphoma & NCT02070393; NCT00850200; NCT02404818; NCT01751412 \\
\hline \multirow[t]{4}{*}{ Sarcoma } & $\begin{array}{l}\text { Chordoma, } \\
\text { chondrosarcoma }\end{array}$ & $\begin{array}{l}\text { NCT00797602; NCT00881595; NCT00901836; NCT0049652; NCT00496119; NCT01449149; NCT01561495; } \\
\text { NCT01182753; NCT01904565; NCT01819831 }\end{array}$ \\
\hline & Spine & NCT01346124; NCT00592345 \\
\hline & Retroperitoneal & NCT01659203; NCT01034566 \\
\hline & Sacrococcygeal & NCT01811394; NCT02986516 \\
\hline $\begin{array}{l}\text { Female } \\
\text { reproductive } \\
\text { system }\end{array}$ & $\begin{array}{l}\text { Rhabdomyosarcoma } \\
\text { Cervical and endometrial }\end{array}$ & $\begin{array}{l}\text { NCT01871766 } \\
\text { NCT03184350 }\end{array}$ \\
\hline
\end{tabular}


techniques should be more valuable to confirm whether the advantage of protons can be transferred into a benefit for clinical outcome and late effects in HNC.

Besides, there are currently still some great challenges in the precision PBT. In addition, in the future, there will be more advances in precision proton radiotherapy to benefit more patients.

\section{Technical developments in precision proton radiotherapy}

The proton planning system and facility are advanced, which makes PBT increasingly precise over time. The target volume is usually larger than the high-dose covered by the Bragg peak. Spread-out Bragg peaks (SOBP) are needed to make sure every tissue element in the target receives the same amount of dose. In the early days, the dose mainly delivered by PSPT used the beam double scattering and range modulation techniques. To spare the normal tissues in the lateral and distal tumor, the aperture and range compensator are usually needed. The drawbacks of scattering technique include broadened lateral penumbra, secondary particles, e.g., neutrons, from the scatters, and need for the numerous pieces of hardware for every treatment field. With the advanced development of computers and technology, the active scanning technique, named IMPT, including intensity-modulated scanning, PBS, and spot scanning, can overcome the drawbacks of the scattering system, obtain better dose conformity, and reduce the integral non-target dose. However, the active scanning technology is very sensitive to organ motion and change, because it delivers the dose to different parts of the target sequentially. Therefore, it is required that the boundary, motion, and changes of GTV and OARs are accurately determined. Meanwhile, the equipment with protons is more advanced with time, which is also very important for precision PBT. In the earliest proton facilities, the beam was fixed in 1 to 2 directions was fixed. To some extent, the restrictions of fixed beam, beam energy, and field size in turn limit the advantage of protons. Currently, most newly constructed facilities have $360^{\circ}$ rotational gantries that allow treatment of tumors at any anatomic site, and the therapy system has the IMPT planning capabilities.

To fully take advantage of the depth-dose benefit, it is more important to define the range of the proton beam as accurately as possible. The range uncertainty in patients mainly arises from CT imaging and calibration, CT resolution, and CT Hounsfield units (HU) to relative stopping power (RSP) conversion [93]. To improve the accuracy of the proton beam range, more advanced devices including simulation MRI, dual-energy CT, and proton CT can be used. The current single-energy CT leads to related uncertainties in the proton range of approximately $3 \%$. To ensure the target received the prescription dose, the range uncertainty should be included, which will lead to the normal tissues around target receiving much more radiation dose. Recently, studies have focused on reducing the range uncertainty and improving its accuracy, and the dual-energy CT was suggested to be used in the proton therapy. Previous studies have reported that dual-energy CT potentially improved the conversion from CT HU to RSP, which could reduce the proton beam range uncertainties by $0.4 \%$ in soft tissues, and reduce the RSP uncertainty from $1.59 \%$ to $0.61 \%$ for homogeneous tissue-equivalent [94, 95]. However, the dual-energy $\mathrm{CT}$ only reduces uncertainty arising from the conversion of CT HU to RSP but cannot eliminate it. Several studies have demonstrated that the proton $\mathrm{CT}$, whose image-formation characteristics are based on the linear stopping power of protons, avoids the uncertainties of mapping $\mathrm{x}-\mathrm{CT} \mathrm{HU}$ values to RSP [96]. Arbor et al. [97] has validated the proton CT benefit based on a Monte Carlo comparison. Studies have demonstrated that the proton $\mathrm{CT}$ has the potential to outperform the accuracy achievable with dual energy CT [98, 99]. Another potential advantage of the proton $\mathrm{CT}$ is that it needs fewer doses to achieve the same quality image [100]. This kind of proton CT device is still currently in development and has not been used in clinical settings.

It is a great challenge to precisely calculate the dose in a treatment planning system. There are mainly two methods to calculate the dose: analytical algorithms and the Monte Carlo method. The accurate calculation dose of the Monte Carlo method is much higher than the former, which is a common method to use at present. Previous studies have analyzed the differences between analytical algorithms and Monte Carlo dose computations in proton therapy [101]. Urie et al. [102] has investigated that the analytical algorithms could not able to precisely predict the effect of range degradation, due to the fact that it is less sensitive to complex geometries and density variations. The study has compared Monte Carlo dose with analytical dose computations based on 525 patients, and found that the analytical method overestimates the dose in the tumor target by nearly $10 \%$; however, the dose in some OAR could be underestimated about $10 \mathrm{~Gy}$ [103]. It has the potential to increase some toxicities. Monte Carlo algorithms should be applied to accurately calculate the dose to improve target coverage and spare the OAR in PBT. Currently, only a few proton centers use the Monte Carlo algorithms. It needs more time to compute the dose, which limits the application in clinical settings. However, with the development of computers, it would take much less time for Monte Carlo computation. 


\section{The effect of anatomical changes in precision proton radiotherapy}

The effect of dose distribution caused by anatomical changes in proton therapy is more sensitive than photon therapy. Therefore, it is very critical to delineate accurately the GTV and monitor motion and changes of GTV and OARs. Apart from training physicians for GTV and OARs delineation with precision, there are several techniques to reduce the effect of dose distribution by anatomical changes. First, MRI can provide more detailed anatomical boundaries for GTV compared with CT images, including NPC, liver cancer, and colorectal cancer. Schmidt et al. [104] reviewed that MRI could apply to wide range of image contrast mechanisms and use to RT treatment planning. In addition, a number of challenges are reviewed: the effects of patient motion during the longtime scan, an estimate of electron density for tissues, MRI is acquired in the radiotherapy treatment position, and the geometrical accuracy. Second, for patients with lung cancer or liver cancer, the tumor movement during treatment with the breath is more significant. To keep the tumor receiving the prescribed dose, anatomic motion management strategies are currently used in proton therapy including respiration gating [105], real-time tumor tracking [106], and breathe and hold techniques [107]. Breathe hold techniques provide a relatively stable breath in phase of radiation therapy, which minimize the breath motion effect. However, patients need to have a better pulmonary function for the technique. Third, periodic imaging in the course of treatment is used to monitor and assess the changes in patient anatomy generated by tissue deformation, tumor shrinkage, weight loss, and so on. Kraanet al. [108] concluded that bulky radiosensitive human papillomavirus-positive tumors and cervical lymph nodes can respond early in the therapy course causing considerable anatomical changes, which might contribute to a less predictable proton dose distribution. It is not clear whether the treatment plan needs to be reformulated. Image-guided radiation therapy (IGRT) [109], cone beam CT (CBCT) or orbital CT (CT-on rail) is usually used to conduct an image scan before each irradiation for photon therapy. However, it has not widely been used in proton centers. Regular CT scanning is used in some studies. However, the optimum internal time of repeated CT scanning has not been defined, and the tracking technique or repeated CT scan causes the patient's exposure to ionizing radiation. Last, adaptive radiotherapy is a promising way to adjust the radiation dose distribution according to the changes of tumors and OARs [110].

\section{Biological effectiveness in precision proton radiotherapy}

The RT treatment planning is made on the basis of the prescription doses to the target and constraints for normal tissues. Proton treatment planning is currently planned and delivered assuming a proton relative biological effectiveness (RBE) relative to photons of 1.1 [111], which has usually been used. To date, there is very different comprehension of the 1.1 of RBE. Some studies considered that 1.1 of $\mathrm{RBE}$ were acceptable in clinical settings, which was an averaged value of measured RBE, neglecting any dependency of RBE on dose, endpoint or proton beam properties. Others disagree that 1.1 of $\mathrm{RBE}$ is an invariable value. In particular, the distal edge of the proton SOBP should be given much attention. The RBE quickly increases as the sharply increasing LET, which will underestimate the effectiveness in the surrounding tissue, causing more unexpected toxicity or complication. In a retrospective subset analysis, patients with oligodendroglioma treated with proton RT developed pseudoprogression earlier compared to photon therapy (48 days versus 131 days). However, there was no difference in those with astrocytoma. The finding suggests the biological effect of proton radiation is different between oligodendroglioma and astrocytoma [112]. Moreover, it is a great challenge to precisely measure the $R B E$ value for the desired position due to the sharp distal fall-off of SOBP. Wouters et al. [113] has investigated the depth and dose dependence of RBE. In addition, the averaged RBE value for entrance, proximal half, distal half, and distal edge was $1.07,1.1,1.17$, and 1.21 , respectively, and the RBE was determined to have dose dependence. Maeda et al. [114] have evaluated the RBE of the spot-scanning beam in different depth of SOBP and found that the distal region showed higher RBE values; these results are in line with those previous studies conducted using PSPT. A study by Jones et al. [115] has demonstrated that the widest RBE ranges existed in low $\alpha / \beta$ value biosystems because of dose per fraction varies and improving linear energy transfer (LET), usually exceed 1.1 even within the SOBP LET range, with lower $\mathrm{RBE}$ values at higher dose per fraction. For tumors with greatly radiosensitive, the $\mathrm{RBE}$ values are usually less than 1.1 and insensitivity to per fraction. Therefore, it is important to reduce the LET in normal tissue due to the fact that RBEs increase with LET. However, all the results were based on the in vitro and animal systems [116]. There are limited published clinical data that would investigate the effectiveness for certain tumors or OARs. To the best of our knowledge, there is only one study by Zhang et al., only in a meeting abstract [117]. It attempted to find the end-of-range $\mathrm{RBE}$ in the temporal lobe based on long-term follow-up data from patients with NPC. The findings showed that the brain-specific end-of-range RBE could be $\geq 1.8,7.3 \%$ higher than what is currently used in clinical settings. The optimal RBE has not been defined. RBE may be different in different biological diseases. The RBE varying with LET, 
physiological and biological factors, and clinical endpoints still requires further research.

\section{Conclusions}

The dosimetric advantage of protons results in a finite range with little or no exit dose and a smaller volume of normal tissue to be irradiated. It is worth noting that the precision is becoming increasingly more important to take advantage of PBT for patients. The technical advances allow that the precision PBT will become widely available, and it may be the lead application in the treatment of cancer in the future. Optimization of the PBT, appropriate integration of the proton beam with chemotherapy, target therapy, biological therapy, or immunotherapy, would further benefit patients with aggressive tumors, providing excellent survival and less toxicity.

\section{Abbreviations}

APBI: Accelerated partial breast irradiation; CBCT: Cone beam CT; COG: Children's Oncology Group; CR: Complete response; DFS: Disease-free survival; DMFS: Distant metastasis-free survival; EC: Esophageal cancer; FDM: Freedom of distant metastasis; HCC: Hepatocellular carcinoma; HNC: Head and neck cancer; HRQOL: Health-related quality of life; HU: Hounsfield units; IGRT: Image-guided radiation therapy; IMPT: Intensity-modulated proton therapy; IMRT: Intensitymodulated radiotherapy; IQ: Intelligence quotient; LET: Linear energy transfer; LGG: Low-grade glioma; LRC: Locoregional control; LRF: Locoregional failure; LRFFS: Locoregional failure-free survival; MGH: Massachusetts General Hospital; NCCN: Comprehensive Cancer Network; NPC: Nasopharyngeal carcinoma; NSCLC: Non-small cell lung cancer; OARs: Organs at risk; OS: Overall survival; PBS: Pencil-beam scattering; PBT: Proton beam therapy; PFS: Progression-free survival; PSPT: Passive scatter proton therapy; QoL: Quality of life; RFS: Relapsefree survival; RSP: Relative stopping power; RT: Radiotherapy; SBPT: Stereotactic body proton radiotherapy; SOBP: Spread-out Bragg peaks; WHO: World Health Organization

\section{Acknowledgements}

The authors thank Hsiao-Ming Lu, Annie Chan, and Li Liu from Francis H. Burr Proton Therapy Center, Department of Radiation Oncology, Massachusetts General Hospital and Harvard Medical School for the help.

\section{Funding}

This work was supported by the grant from the Key Research Development Program of Shan Dong province (2016CYJS01A03) and Science Technology Program of Jinan (201805051).

\section{Availability of data and materials}

The dataset supporting the conclusions of this article is included within the article.

\section{Authors' contributions}

JMY designed the study. MH, LYJ, XLC, and JGZ coordinated and drafted the manuscript. MH edited and finalized the drafting of the manuscript. All authors read and approved the final manuscript.

\section{Ethics approval and consent to participate}

These issues are not applicable for this review.

\section{Consent for publication}

Not applicable.

\section{Competing interests}

The authors declare that they have no competing interests.

\section{Publisher's Note}

Springer Nature remains neutral with regard to jurisdictional claims in published maps and institutional affiliations.

\section{Author details}

'Shandong Cancer Hospital Affiliated to Shandong University, Jinan, China. ${ }^{2}$ Shandong Academy of Medical Sciences, Jinan, China. ${ }^{3}$ Departments of Radiation Oncology and Shandong Province Key Laboratory of Radiation Oncology, Shandong Cancer Hospital and Institute, Jinan, China. ${ }^{4}$ Province Key Laboratory of Medical Physics and Technology, Center of Medical Physics and Technology, Hefei Institutes of Physical Science, Chinese Academy of Sciences, Hefei, Anhui, China. ${ }^{5}$ Departments of Radiation Oncology, Zibo Wanjie Cancer Hospital, Zibo, Shandong, China.

Received: 1 October 2018 Accepted: 28 November 2018

Published online: 12 December 2018

\section{References}

1. Mohan R, Grosshans D. Proton therapy - present and future. Adv Drug Deliv Rev. 2017;109:26-44 https://doi.org/10.1016/j.addr.2016.11.006.

2. Wilson RR. Radiological use of fast protons. Radiology. 1946;47:487-91 https://doi.org/10.1148/47.5.487.

3. Lawrence JH, Tobias CA, Born JL, RK MCOMBS, Roberts JE, Anger HO, et al. Pituitary irradiation with high-energy proton beams: a preliminary report. Cancer Res. 1958;18:121-34.

4. Kjellberg RN, Koehler AM, Preston WM, Sweet WH. Stereotaxic instrument for use with the Bragg peak of a proton beam. Confin Neurol. 1962;22:183-9.

5. Romesser PB, Cahlon O, Scher ED, Hug EB, Sine K, DeSelm C, et al. Proton beam reirradiation for recurrent head and neck cancer: multi-institutional report on feasibility and early outcomes. Int J Radiat Oncol Biol Phys. 2016; 95:386-95 https://doi.org/10.1016/j.jprobp.2016.02.036.

6. Phan J, Sio TT, Nguyen TP, Takiar V, Gunn GB, Garden AS, et al. Reirradiation of head and neck cancers with proton therapy: outcomes and analyses. Int J Radiat Oncol Biol Phys. 2016;96:30-41 https://doi.org/ 10.1016/j.jprobp.2016.03.053.

7. Chao HH, Berman AT, Simone CB 2nd, Ciunci C, Gabriel P, Lin H, et al. Multi-institutional prospective study of reirradiation with proton beam radiotherapy for locoregionally recurrent non-small cell lung cancer. J Thorac Oncol. 2017;12:281-92 https://doi.org/10.1016/j.jtho.2016.10.018.

8. Ho JC, Nguyen QN, Li H, Allen PK, Zhang X, Liao Z, et al. Reirradiation of thoracic cancers with intensity modulated proton therapy. Pract Radiat Oncol. 2018;8:58-65 https://doi.org/10.1016/.jprro.2017.07.002.

9. Oshiro Y, Mizumoto M, Okumura T, Fukuda K, Fukumitsu N, Abei M, et al. Analysis of repeated proton beam therapy for patients with hepatocellular carcinoma. Radiother Oncol. 2017;123:240-5 https://doi.org/10.1016/j. radonc.2017.03.004.

10. Haaskogan D, Indelicato D, Paganetti H, Esiashvili N, Mahajan A, Yock T, et al. National Cancer Institute workshop on proton therapy for children: considerations regarding brainstem injury. Int J Radiat Oncol Biol Phys. 2018;101:152-68.

11. Yock TI, Yeap BY, Ebb DH, Weyman E, Eaton BR, Sherry NA, et al. Long-term toxic effects of proton radiotherapy for paediatric medulloblastoma: a phase 2 single-arm study. Lancet Oncol. 2016;17:287-98 https://doi.org/10.1016/ s1470-2045(15)00167-9.

12. Mouw KW, Sethi RV, Yeap BY, SM MD, Chen YL, Tarbell NJ, et al. Proton radiation therapy for the treatment of retinoblastoma. Int J Radiat Oncol Biol Phys. 2014;90:863-9 https://doi.org/10.1016/j.jprobp.2014.07.031.

13. Rombi B, Ares C, Hug EB, Schneider R, Goitein G, Staab A, et al. Spotscanning proton radiation therapy for pediatric chordoma and chondrosarcoma: clinical outcome of 26 patients treated at Paul scherrer institute. Int J Radiat Oncol Biol Phys. 2013;86:578-84 https://doi.org/10. 1016/j.ijrobp.2013.02.026.

14. Ares C, Albertini F, Frei-Welte M, Bolsi A, Grotzer MA, Goitein G, et al. Pencil beam scanning proton therapy for pediatric intracranial ependymoma. $J$ Neuro-Oncol. 2016;128:137-45 https://doi.org/10.1007/s1 1060-016-2090-4.

15. Bishop AJ, Greenfield B, Mahajan A, Paulino AC, Okcu MF, Allen PK, et al. Proton beam therapy versus conformal photon radiation therapy for childhood craniopharyngioma: multi-institutional analysis of outcomes, cyst dynamics, and toxicity. Int J Radiat Oncol Biol Phys. 2014;90:354-61 https:// doi.org/10.1016/j.jijobp.2014.05.051

16. Greenberger BA, Pulsifer MB, Ebb DH, SM MD, Jones RM, Butler WE, et al. Clinical outcomes and late endocrine, neurocognitive, and visual profiles of proton radiation for pediatric low-grade gliomas. Int J Radiat Oncol Biol Phys. 2014;89:1060-8 https://doi.org/10.1016/j.jirobp.2014.04.053. 
17. McGovern SL, Okcu MF, Munsell MF, Kumbalasseriyil N, Grosshans DR, McAleer MF, et al. Outcomes and acute toxicities of proton therapy for pediatric atypical teratoid/rhabdoid tumor of the central nervous system. Int J Radiat Oncol Biol Phys. 2014;90:1143-52 https://doi.org/10.1016/j.jjrobp. 2014.08.354

18. Weber DC, Murray FR, Correia D, Bolsi A, Frei-Welte M, Pica A, et al. Pencil beam scanned protons for the treatment of patients with Ewing sarcoma. Pediatr Blood Cancer. 2017;64 https://doi.org/10.1002/pbc.26688.

19. Eaton BR, Esiashvili N, Kim S, Patterson B, Weyman EA, Thornton LT, et al. Endocrine outcomes with proton and photon radiotherapy for standard risk medulloblastoma. Neuro-Oncology. 2016;18:881-7 https://doi.org/10.1093/ neuonc/nov302.

20. Pulsifer MB, Sethi RV, Kuhlthau KA, SM MD, Tarbell NJ, Yock TI. Early cognitive outcomes following proton radiation in pediatric patients with brain and central nervous system tumors. Int J Radiat Oncol Biol Phys. 2015; 93:400-7 https://doi.org/10.1016/j.jjrobp.2015.06.012.

21. Yock TI, Bhat S, Szymonifka J, Yeap BY, Delahaye J, Donaldson SS, et al. Quality of life outcomes in proton and photon treated pediatric brain tumor survivors. Radiother Oncol. 2014;113:89-94 https://doi.org/10.1016/j. radonc.2014.08.017.

22. Leiser D, Calaminus G, Malyapa R, Bojaxhiu B, Albertini F, Kliebsch U, et al. Tumour control and quality of life in children with rhabdomyosarcoma treated with pencil beam scanning proton therapy. Radiother Oncol. 2016; 120:163-8 https://doi.org/10.1016/j.radonc.2016.05.013.

23. Bavle A, Tewari S, Sisson A, Chintagumpala M, Anderson M, Paulino AC. Meta-analysis of the incidence and patterns of second neoplasms after photon craniospinal irradiation in children with medulloblastoma. Pediatr Blood Cancer. 2018;65:e27095 https://doi.org/10.1002/pbc.27095.

24. Sethi RV, Shih HA, Yeap BY, Mouw KW, Petersen R, Kim DY, et al. Second nonocular tumors among survivors of retinoblastoma treated with contemporary photon and proton radiotherapy. Cancer. 2014;120:126-33 https://doi.org/10.1002/cncr.28387.

25. Maquilan G, Grover S, Alonso-Basanta M, Lustig RA. Acute toxicity profile of patients with low-grade gliomas and meningiomas receiving proton therapy. Am J Clin Oncol. 2014;37:438-43 https://doi.org/10.1097/COC. Ob013e31827de86b.

26. Wilkinson B, Morgan H, Gondi V, Larson GL, Hartsell WF, Laramore GE, et al. Low levels of acute toxicity associated with proton therapy for low-grade glioma: a proton collaborative group study. Int J Radiat Oncol Biol Phys. 2016;96:E135 https://doi.org/10.1016/j.jijobp.2016.06.930.

27. Shih HA, Sherman JC, Nachtigall LB, Colvin MK, Fullerton BC, Daartz J, et al. Proton therapy for low-grade gliomas: results from a prospective trial. Cancer. 2015;121:1712-9 https://doi.org/10.1002/cncr.29237.

28. MW MD, Plankenhorn DA, KP MM, Henderson MA, Dropcho EJ, Shah MV, et al. Proton therapy for atypical meningiomas. J Neuro-Oncol. 2015;123: 123-8 https://doi.org/10.1007/s11060-015-1770-9.

29. Vlachogiannis P, Gudjonsson O, Montelius A, Grusell E, Isacsson U, Nilsson K, et al. Hypofractionated high-energy proton-beam irradiation is an alternative treatment for WHO grade I meningiomas. Acta Neurochir. 2017; 159:2391-400 https://doi.org/10.1007/s00701-017-3352-4.

30. Stacchiotti S, Sommer J. Building a global consensus approach to chordoma: a position paper from the medical and patient community. Lancet Oncol. 2015; 16:e71-83 https:/doi.org/10.1016/s1470-2045(14)71190-8.

31. Weber DC, Badiyan S, Malyapa R, Albertini F, Bolsi A, Lomax AJ, et al. Longterm outcomes and prognostic factors of skull-base chondrosarcoma patients treated with pencil-beam scanning proton therapy at the Paul Scherrer Institute. Neuro-Oncology. 2016;18:236-43 https://doi.org/10.1093/ neuonc/nov154

32. Weber DC, Malyapa R, Albertini F, Bolsi A, Kliebsch U, Walser M, et al. Long term outcomes of patients with skull-base low-grade chondrosarcoma and chordoma patients treated with pencil beam scanning proton therapy. Radiother Oncol. 2016;120:169-74 https://doi. org/10.1016/j.radonc.2016.05.011.

33. Zhou J, Yang B, Wang $X$, Jing Z. Comparison of the effectiveness of radiotherapy with photons and particles for Chordoma after surgery: a meta-analysis. World Neurosurg. 2018;117:46-53 https://doi.org/10.1016/j. wneu.2018.05.209.

34. Feuvret L, Bracci S, Calugaru V, Bolle S, Mammar H, De Marzi L, et al. Efficacy and safety of adjuvant proton therapy combined with surgery for chondrosarcoma of the skull base: a retrospective, population-based study. Int J Radiat Oncol Biol Phys. 2016;95:312-21 https://doi.org/10.1016/j.jprobp.2015.12.016.
35. Stieb S, Snider JW 3rd, Placidi L, Kliebsch U, Lomax AJ, Schneider RA, et al. Long-term clinical safety of high-dose proton radiation therapy delivered with pencil beam scanning technique for extracranial Chordomas and chondrosarcomas in adult patients: clinical evidence of spinal cord tolerance. Int J Radiat Oncol Biol Phys. 2018;100:218-25 https://doi.org/10. 1016/j.ijrobp.2017.08.037.

36. Wattson DA, Tanguturi SK, Spiegel DY, Niemierko A, Biller BM, Nachtigall LB, et al. Outcomes of proton therapy for patients with functional pituitary adenomas. Int J Radiat Oncol Biol Phys. 2014;90:532-9 https://doi.org/10. 1016/j.jijobp.2014.06.068.

37. Romesser PB, Cahlon O, Scher E, Zhou Y, Berry SL, Rybkin A, et al. Proton beam radiation therapy results in significantly reduced toxicity compared with intensity-modulated radiation therapy for head and neck tumors that require ipsilateral radiation. Radiother Oncol. 2016;118:286-92 https://doi. org/10.1016/j.radonc.2015.12.008.

38. Russo AL, Adams JA, Weyman EA, Busse PM, Goldberg SI, Varvares M, et al. Long-term outcomes after proton beam therapy for Sinonasal squamous cell carcinoma. Int J Radiat Oncol Biol Phys. 2016;95:368-76 https://doi.org/ 10.1016/j.ijrobp.2016.02.042.

39. Patel SH, Wang Z, Wong WW, Murad MH, Buckey CR, Mohammed K, et al. Charged particle therapy versus photon therapy for paranasal sinus and nasal cavity malignant diseases: a systematic review and meta-analysis. Lancet Oncol. 2014;15:1027-38 https://doi.org/10.1016/s14702045(14)70268-2.

40. Chan A, Adams JA, Weyman E, Parambi R, Goldsmith T, Holman A, et al. A phase II trial of proton radiation therapy with chemotherapy for nasopharyngeal carcinoma. Int J Radiat Oncol Biol Phys. 2012;84: S151-S52.

41. Lewis GD, Holliday EB, Kocak-Uzel E, Hernandez M, Garden AS, Rosenthal DI, et al. Intensity-modulated proton therapy for nasopharyngeal carcinoma: decreased radiation dose to normal structures and encouraging clinical outcomes. Head Neck. 2016;38:E1886-E95.

42. Holliday EB, Garden AS, Rosenthal DI, Fuller CD, Morrison WH, Gunn GB, et al. Proton therapy reduces treatment-related toxicities for patients with nasopharyngeal cancer: a case-match control study of intensity-modulated proton therapy and intensity-modulated photon therapy. Int J Particle Ther. 2015;2:19-28 https://doi.org/10.14338/IJPT-15-00011.1.

43. Sio TT, Lin HK, Shi Q, Gunn GB, Cleeland CS, Lee JJ, et al. Intensitymodulated proton therapy (IMPT) versus intensity-modulated photon radiotherapy (IMRT) for oropharyngeal cancer: first comparative results of patient-reported outcomes. Int J Radiat Oncol Biol Phys. 2016;95: 1107.

44. Gunn GB, Blanchard P, Garden AS, Zhu XR, Fuller CD, Mohamed AS, et al. Clinical outcomes and patterns of disease recurrence after intensity modulated proton therapy for oropharyngeal squamous carcinoma. Int J Radiat Oncol Biol Phys. 2016;95:360-7 https://doi.org/ 10.1016/j.jijrobp.2016.02.021.

45. Blanchard P, Garden AS, Gunn GB, Rosenthal DI, Morrison WH, Hernandez $M$, et al. Intensity-modulated proton beam therapy (IMPT) versus intensitymodulated photon therapy (IMRT) for patients with oropharynx cancer - a case matched analysis. Radiother Oncol. 2016;120:48-55 https://doi.org/10. 1016/j.radonc.2016.05.022.

46. Lane AM, Kim IK, Gragoudas ES. Long-term risk of melanoma-related mortality for patients with uveal melanoma treated with proton beam therapy. Jama Ophthalmol. 2015;133:792-6 https://doi.org/10.1001/ jamaophthalmol.2015.0887.

47. Seibel I, Cordini D, Rehak M, Hager A, Riechardt Al, Boker A, et al. Local recurrence after primary proton beam therapy in uveal melanoma: risk factors, retreatment approaches, and outcome. Am J Ophthalmol. 2015;160; 628-36 https://doi.org/10.1016/j.ajo.2015.06.017.

48. Papakostas TD, Lane AM, Morrison M, Gragoudas ES, Kim IK. Long-term outcomes after proton beam irradiation in patients with large choroidal melanomas. Jama Ophthalmol. 2017;135:1191-6 https://doi.org/10.1001/ jamaophthalmol.2017.3805.

49. Verma V, Mehta MP. Clinical outcomes of proton radiotherapy for uveal melanoma. Clin Oncol (R Coll Radiol). 2016;28:e17-27 https://doi.org/10. 1016/j.clon.2016.01.034.

50. Bensoussan E, Thariat J, Maschi C, Delas J, Schouver ED, Herault J, et al. Outcomes after proton beam therapy for large choroidal melanomas in 492 patients. Am J Ophthalmol. 2016;165:78-87 https://doi.org/10.1016/j.ajo. 2016.02.027. 
51. Holliday EB, Esmaeli B, Pinckard J, Garden AS, Rosenthal DI, Morrison $\mathrm{WH}$, et al. A multidisciplinary orbit-sparing treatment approach that includes proton therapy for epithelial tumors of the orbit and ocular adnexa. Int J Radiat Oncol Biol Phys. 2016;95:344-52 https://doi.org/10. 1016/j.jijrobp.2015.08.008.

52. Esmaeli B, Yin VT, Hanna EY, Kies MS, William WN Jr, Bell D, et al. Eye-sparing multidisciplinary approach for the management of lacrimal gland carcinoma. Head Neck. 2016;38:1258-62 https://doi.org/10.1002/hed.24433.

53. Thariat J, Maschi C, Lanteri S, Peyrichon ML, Baillif S, Herault J, et al. Dry eye syndrome after proton therapy of ocular melanomas. Int J Radiat Oncol Biol Phys. 2017:98:142-51 https://doi.org/10.1016/j.jirobp.2017.01.199.

54. Thariat J, Jacob S, Caujolle JP, Maschi C, Baillif S, Angellier G, et al. Cataract avoidance with proton therapy in ocular melanomas. Invest Ophthalmol Vis Sci. 2017:58:5378-86 https://doi.org/10.1167/iovs.17-22557.

55. Konstantinidis $L$, Roberts $D$, Errington RD, Kacperek A, Heimann $H$, Damato B. Transpalpebral proton beam radiotherapy of choroidal melanoma. Br J Ophthalmol. 2015;99:232-5 https://doi.org/10.1136/ bjophthalmol-2014-305313.

56. Bush DA, Cheek G, Zaheer S, Wallen J, Mirshahidi H, Katerelos A, et al. Highdose hypofractionated proton beam radiation therapy is safe and effective for central and peripheral early-stage non-small cell lung cancer: results of a 12-year experience at Loma Linda University medical center. Int J Radiat Oncol Biol Phys. 2013;86:964-8 https://doi.org/10.1016/j.jirobp.2013.05.002.

57. Chang JY, Zhang W, Komaki R, Choi NC, Chan S, Gomez D, et al. Long-term outcome of phase $1 / / I$ prospective study of dose-escalated proton therapy for early-stage non-small cell lung cancer. Radiother Oncol. 2017;122:274-80 https://doi.org/10.1016/j.radonc.2016.10.022.

58. Nantavithya C, Gomez DR, Wei X, Komaki R, Liao Z, Lin SH, et al. Phase 2 study of stereotactic body radiation therapy and stereotactic body proton therapy for high-risk, medically inoperable, early-stage non-small cell lung Cancer. Int J Radiat Oncol Biol Phys. 2018;101:558-63 https://doi.org/10. 1016/j.jijobp.2018.02.022.

59. Nakayama H, Satoh H, Sugahara S, Kurishima K, Tsuboi K, Sakurai H, et al. Proton beam therapy of stage II and III non-small-cell lung cancer. Int J Radiat Oncol Biol Phys. 2011;81:979-84 https://doi.org/10. 1016/j.jijrobp.2010.06.024

60. Nguyen QN, Ly NB, Komaki R, Levy LB, Gomez DR, Chang JY, et al. Longterm outcomes after proton therapy, with concurrent chemotherapy, for stage II-III inoperable non-small cell lung cancer. Radiother Oncol. 2015;115: 367-72 https://doi.org/10.1016/j.radonc.2015.05.014.

61. Chang JY, Verma V, Li M, Zhang W, Komaki R, Lu C, et al. Proton beam radiotherapy and concurrent chemotherapy for Unresectable stage III nonsmall cell lung Cancer: final results of a phase 2 study. JAMA Oncol. 2017;3: e172032 https://doi.org/10.1001/jamaoncol.2017.2032.

62. Oshiro Y, Okumura T, Kurishima K, Homma S, Mizumoto M, Ishikawa H, et al High-dose concurrent chemo-proton therapy for stage III NSCLC: preliminary results of a phase II study. J Radiat Res. 2014;55:959-65 https:// doi.org/10.1093/jrr/rru034.

63. Chang JY, Komaki R, Lu C, Wen HY, Allen PK, Tsao A, et al. Phase 2 study of high-dose proton therapy with concurrent chemotherapy for unresectable stage III nonsmall cell lung cancer. Cancer. 2011;117:4707-13 https://doi. org/10.1002/cncr.26080.

64. Liao Z, Lee JJ, Komaki R, Gomez DR, O'Reilly MS, Fossella FV, et al. Bayesian adaptive randomization trial of passive scattering proton therapy and intensity-modulated photon radiotherapy for locally advanced non-smallcell lung Cancer. J Clin Oncol. 2018;36:1813-22 https://doi.org/10.1200/jco. 2017.74.0720.

65. Liao Z. RTOG 1308 Phase III randomized trial comparing overall survival after photon versus proton chemoradiotherapy for inoperable stage II-IIIB NSCLC. Available from URL: https://clinicaltrials.gov/ct2/show/record/NCT01993810. Accessed 5 Sept 2018

66. Bush DA, Do S, Lum S, Garberoglio C, Mirshahidi H, Patyal B, et al. Partial breast radiation therapy with proton beam: 5-year results with cosmetic outcomes. Int J Radiat Oncol Biol Phys. 2014;90:501-5 https://doi.org/10. 1016/j.jijrobp.2014.05.1308.

67. Verma V, Iftekaruddin Z, Badar N, Hartsell W, Han-Chih Chang J, Gondi V, et al. Proton beam radiotherapy as part of comprehensive regional nodal irradiation for locally advanced breast cancer. Radiother Oncol. 2017;123: 294-8 https://doi.org/10.1016/j.radonc.2017.04.007.

68. Cuaron JJ, Chon B, Tsai H, Goenka A, DeBlois D, Ho A, et al. Early toxicity in patients treated with postoperative proton therapy for locally advanced breast cancer. Int J Radiat Oncol Biol Phys. 2015;92:284-91 https://doi.org/ 10.1016/j.jijrobp.2015.01.005.

69. SM MD, Patel SA, Hickey S, Specht M, Isakoff SJ, Gadd M, et al. Proton therapy for breast cancer after mastectomy: early outcomes of a prospective clinical trial. Int J Radiat Oncol Biol Phys. 2013;86:484-90 https:// doi.org/10.1016/j.jijobp.2013.01.038.

70. Stick LB, Yu J, Maraldo MV, Aznar MC, Pedersen AN, Bentzen SM, et al. Joint estimation of cardiac toxicity and recurrence risks after comprehensive nodal photon versus proton therapy for breast Cancer. Int J Radiat Oncol Biol Phys. 2017;97:754-61 https://doi.org/10.1016/j. ijrobp.2016.12.008.

71. Ishikawa H, Hashimoto T, Moriwaki T, Hyodo I, Hisakura K, Terashima H, et al Proton beam therapy combined with concurrent chemotherapy for esophageal cancer. Anticancer Res. 2015;35:1757-62.

72. Prayongrat $\mathrm{A}, \mathrm{Xu} \mathrm{C}, \mathrm{Li} \mathrm{H}, \mathrm{Lin} \mathrm{SH}$. Clinical outcomes of intensity modulated proton therapy and concurrent chemotherapy in esophageal carcinoma: a single institutional experience. Adv Radiat Oncol. 2017;2:301-7 https://doi. org/10.1016/j.adro.2017.06.002.

73. Xi M, Xu C, Liao Z, Chang JY, Gomez DR, Jeter M, et al. Comparative outcomes after definitive chemoradiotherapy using proton beam therapy versus intensity modulated radiation therapy for esophageal Cancer: a retrospective, single-institutional analysis. Int J Radiat Oncol Biol Phys. 2017; 99:667-76 https://doi.org/10.1016/j.jijrobp.2017.06.2450.

74. Davuluri R, Jiang W, Fang P, Xu C, Komaki R, Gomez DR, et al. Lymphocyte nadir and esophageal cancer survival outcomes after chemoradiation therapy. Int J Radiat Oncol Biol Phys. 2017;99:128-35 https://doi.org/10. 1016/j.jjrobp.2017.05.037

75. Kim TH, Park JW, Kim YJ, Kim BH, Woo SM, Moon SH, et al. Phase I doseescalation study of proton beam therapy for inoperable hepatocellular carcinoma. Cancer Res Treat. 2015;47:34-45 https://doi.org/10.4143/crt.2013.218,

76. Hong TS, Wo JY, Yeap BY, Ben-Josef E, El MD, Blaszkowsky LS, et al. Multiinstitutional phase II study of high-dose hypofractionated proton beam therapy in patients with localized, unresectable hepatocellular carcinoma and intrahepatic cholangiocarcinoma. J Clin Oncol. 2016;34:460-8 https:// doi.org/10.1200/jco.2015.64.2710.

77. Kimura K, Nakamura T, Ono T, Azami Y, Suzuki M, Wada H, et al. Clinical results of proton beam therapy for hepatocellular carcinoma over $5 \mathrm{~cm}$. Hepatol Res. 2017;47:1368-74 https://doi.org/10.1111/hepr.12874.

78. Bush DA, Smith JC, Slater JD, Volk ML, Reeves ME, Cheng J, et al. Randomized clinical trial comparing proton beam radiation therapy with transarterial chemoembolization for hepatocellular carcinoma: results of an interim analysis. Int J Radiat Oncol Biol Phys. 2016;95:477-82 https://doi.org/ 10.1016/j.jirobp.2016.02.027.

79. Fukuda K, Okumura T, Abei M, Fukumitsu N, Ishige K, Mizumoto M, et al. Long-term outcomes of proton beam therapy in patients with previously untreated hepatocellular carcinoma. Cancer Sci. 2017;108:497-503 https:// doi.org/10.1111/cas.13145.

80. Lee SU, Park JW, Kim TH, Kim YJ, Woo SM, Koh YH, et al. Effectiveness and safety of proton beam therapy for advanced hepatocellular carcinoma with portal vein tumor thrombosis. Strahlenther Onkol. 2014;190:806-14 https:// doi.org/10.1007/s00066-014-0604-6.

81. Apisarnthanarax S, Saini J, O'Ryan-Blair A, Castro J, Bowen SR. Intensity modulated proton therapy with advanced planning techniques in a challenging hepatocellular carcinoma patient. Cureus. 2017;9:e1674 https:// doi.org/10.7759/cureus.1674

82. Takagi M, Demizu Y, Terashima K, Fujii O, Jin D, Niwa Y, et al. Long-term outcomes in patients treated with proton therapy for localized prostate cancer. Cancer Med. 2017:6:2234-43 https://doi.org/10.1002/cam4.1159.

83. Bryant C, Smith TL, Henderson RH, Hoppe BS, Mendenhall WM, Nichols RC, et al. Five-year biochemical results, toxicity, and patient-reported quality of life after delivery of dose-escalated image guided proton therapy for prostate Cancer. Int J Radiat Oncol Biol Phys. 2016;95:422-34 https://doi.org/ 10.1016/j.jijobp.2016.02.038.

84. Ho CK, Bryant CM, Mendenhall NP, Henderson RH, Mendenhall WM, Nichols $\mathrm{RC}$, et al. Long-term outcomes following proton therapy for prostate cancer in young men with a focus on sexual health. Acta Oncol. 2018;57:582-8 https://doi.org/10.1080/0284186x.2018.1427886.

85. Henderson RH, Bryant C, Hoppe BS, Nichols RC, Mendenhall WM, Flampouri $S$, et al. Five-year outcomes from a prospective trial of image-guided accelerated hypofractionated proton therapy for prostate cancer. Acta Oncol. 2017;56:963-70 https://doi.org/10.1080/0284186x.2017.1287946. 
86. Nakajima K, Iwata H, Ogino H, Hattori Y, Hashimoto S, Nakanishi M, et al. Acute toxicity of image-guided hypofractionated proton therapy for localized prostate cancer. Int J Clin Oncol. 2018;23:353-60 https://doi.org/10. 1007/s10147-017-1209-8

87. Vargas CE, Hartsell WF, Dunn M, Keole SR, Doh L, Eisenbeisz E, et al. Hypofractionated versus standard fractionated proton-beam therapy for low-risk prostate cancer: interim results of a randomized trial PCG GU 002. Am J Clin Oncol. 2018;41:115-20 https://doi.org/10.1097/coc. 0000000000000241.

88. Chung H, Polf J, Badiyan S, Biagioli M, Fernandez D, Latifi K, et al. Rectal dose to prostate cancer patients treated with proton therapy with or without rectal spacer. J Appl Clin Med Phys. 2017;18:32-9 https://doi.org/10. 1002/acm2.12001.

89. Moteabbed M, Trofimov A, Sharp GC, Wang Y, Zietman AL, Efstathiou JA, et al. Proton therapy of prostate cancer by anterior-oblique beams: implications of setup and anatomy variations. Phys Med Biol. 2017;62: 1644-60 https://doi.org/10.1088/1361-6560/62/5/1644.

90. Group PTC-O. Particle therapy facilities in operation Available from URL: https://www.ptcog.ch/index.php/facilities-in-operation. Accessed 18 Sept 2018.

91. Group PTC-O. Particle therapy facilities under construction. Available from URL: https://www.ptcog.ch/index.php/facilities-under-construction. Accessed 18 Sept 2018

92. Group PTC-O. Clinical trials for particle therapy. Available from URL: https:// www.ptcog.ch/index.php/clinical-protocols. Accessed 13 Nov 2017.

93. Paganetti $\mathrm{H}$. Range uncertainties in proton therapy and the role of Monte Carlo simulations. Phys Med Biol. 2012;57:R99-117 https://doi.org/10.1088/ 0031-9155/57/11/r99.

94. Bar E, Lalonde A, Royle G, Lu HM, Bouchard H. The potential of dual-energy CT to reduce proton beam range uncertainties. Med Phys. 2017:44:2332-44 https://doi.org/10.1002/mp.12215

95. Bar E, Lalonde A, Zhang R, Jee KW, Yang K, Sharp G, et al. Experimental validation of two dual-energy $C T$ methods for proton therapy using heterogeneous tissue samples. Med Phys. 2018;45:48-59 https://doi.org/10. 1002/mp.12666

96. Doolan PJ, Testa M, Sharp G, Bentefour EH, Royle G, Lu HM. Patient-specific stopping power calibration for proton therapy planning based on singledetector proton radiography. Phys Med Biol. 2015;60:1901-17 https://doi. org/10.1088/0031-9155/60/5/1901.

97. Arbor N, Dauvergne D, Dedes G, Letang JM, Parodi K, Quinones CT, et al. Monte Carlo comparison of $\mathrm{x}$-ray and proton $\mathrm{CT}$ for range calculations of proton therapy beams. Phys Med Biol. 2015;60:7585-99 https://doi.org/10. 1088/0031-9155/60/19/7585

98. Hudobivnik N, Schwarz F, Johnson T, Agolli L, Dedes G, Tessonnier T, et al. Comparison of proton therapy treatment planning for head tumors with a pencil beam algorithm on dual and single energy CT images. Med Phys. 2016:43:495 https://doi.org/10.1118/1.4939106.

99. Giacometti V, Bashkirov VA, Piersimoni P, Guatelli S, Plautz TE, Sadrozinski $\mathrm{HF}$, et al. Software platform for simulation of a prototype proton CT scanner. Med Phys. 2017:44:1002-16 https://doi.org/10.1002/mp.12107.

100. Sadrozinski HF, Geoghegan T, Harvey E, Johnson RP, Plautz TE, Zatserklyaniy $A$, et al. Operation of the preclinical head scanner for proton CT. Nucl Instrum Methods Phys Res A. 2016;831:394-9 https://doi.org/10.1016/j.nima. 2016.02.001.

101. Titt U, Sahoo N, Ding X, Zheng Y, Newhauser WD, Zhu XR, et al. Assessment of the accuracy of an MCNPX-based Monte Carlo simulation model for predicting three-dimensional absorbed dose distributions. Phys Med Biol. 2008:53:4455-70 https://doi.org/10.1088/0031-9155/53/16/016.

102. Urie M, Goitein M, Holley WR, Chen GT. Degradation of the Bragg peak due to inhomogeneities. Phys Med Biol. 1986;31:1-15.

103. Yepes $P$, Adair A, Grosshans D, Mirkovic D, Poenisch F, Titt U, et al. Comparison of Monte Carlo and analytical dose computations for intensity modulated proton therapy. Phys Med Biol. 2018;63:045003 https://doi.org/ 10.1088/1361-6560/aaa845

104. Schmidt MA, Payne GS. Radiotherapy planning using MRI. Phys Med Biol. 2015:60:R323-61 https://doi.org/10.1088/0031-9155/60/22/r323.

105. Flejmer AM, Edvardsson A, Dohlmar F, Josefsson D, Nilsson M, Witt Nystrom $P$, et al. Respiratory gating for proton beam scanning versus photon 3D-CRT for breast cancer radiotherapy. Acta Oncol. 2016;55:577-83 https://doi.org/ 10.3109/0284186x.2015.1120883.
106. Riboldi M, Orecchia R, Baroni G. Real-time tumour tracking in particle therapy: technological developments and future perspectives. Lancet Oncol. 2012;13:e383-91 https://doi.org/10.1016/s1470-2045(12)70243-7.

107. Lin M, Jolinta L, Feigenberg SJ, Mehta MP, Dsouza WD, Langen KM. Breathhold intensity modulated proton therapy (BH-IMPT) for lung SBRT: feasibility study. Int J Radiat Oncol Biol Phys. 2014;90:S142-S42.

108. Kraan AC, van de Water S, Teguh DN, Al-Mamgani A, Madden T, Kooy HM, et al. Dose uncertainties in IMPT for oropharyngeal cancer in the presence of anatomical, range, and setup errors. Int J Radiat Oncol Biol Phys. 2013;87: 888-96 https://doi.org/10.1016/j.jijobp.2013.09.014

109. Schwarz M. SP-0499: the need for adaptive approaches in proton therapy (compared to photons). Radiother Oncol. 2016;119:S237-S37.

110. Park YK, Sharp GC, Phillips J, Winey BA. Proton dose calculation on scattercorrected CBCT image: feasibility study for adaptive proton therapy. Med Phys. 2015;42:4449-59 https://doi.org/10.1118/1.4923179.

111. Paganetti $H$. Relative biological effectiveness (RBE) values for proton beam therapy. Variations as a function of biological endpoint, dose, and linear energy transfer. Phys Med Biol. 2014;59:R419-72 https:/doi.org/10.1088/ 0031-9155/59/22/r419.

112. Bronk JK, Guha-Thakurta N, Allen PK, Mahajan A, Grosshans DR, SL MG Analysis of pseudoprogression after proton or photon therapy of 99 patients with low grade and anaplastic glioma. Clin Transl Radiat Oncol. 2018;9:30-4 https://doi.org/10.1016/j.ctro.2018.01.002

113. Wouters BG, Skarsgard LD, Gerweck LE, Carabe-Fernandez A, Wong M, Durand RE, et al. Radiobiological intercomparison of the $160 \mathrm{MeV}$ and 230 MeV proton therapy beams at the Harvard cyclotron laboratory and at Massachusetts General Hospital. Radiat Res. 2015;183:174-87 https://doi.org/ $10.1667 /$ rr13795.1.

114. Maeda K, Yasui H, Matsuura T, Yamamori T, Suzuki M, Nagane M, et al. Evaluation of the relative biological effectiveness of spot-scanning proton irradiation in vitro. J Radiat Res. 2016;57:307-11 https://doi.org/ 10.1093/jrr/rrv101.

115. Jones B. Clinical radiobiology of proton therapy: modeling of RBE. Acta Oncol. 2017;56:1374-8 https://doi.org/10.1080/0284186x.2017.1343496.

116. Mairani A, Dokic I, Magro G, Tessonnier T, Bauer J, Bohlen T, et al. A phenomenological relative biological effectiveness approach for proton therapy based on an improved description of the mixed radiation field. Phys Med Biol. 2017;62:1378-95 https://doi.org/10.1088/1361-6560/aa51f7.

117. Zhang Y. Estimating end-of-range RBE in temporal lobe based on long-term flow-up data from patients with nasopharyngeal carcinoma. In: 57th PTCOG meeting; 2018.

Ready to submit your research? Choose BMC and benefit from

- fast, convenient online submission

- thorough peer review by experienced researchers in your field

- rapid publication on acceptance

- support for research data, including large and complex data types

- gold Open Access which fosters wider collaboration and increased citations

- maximum visibility for your research: over $100 \mathrm{M}$ website views per year

At $\mathrm{BMC}$, research is always in progress.

Learn more biomedcentral.com/submissions 